\title{
Leadership Practices of a Principal in a High School with a High Teacher Retention Rate
}

\author{
Ronald A. Branch II \\ West Virginia University
}

Follow this and additional works at: https://researchrepository.wvu.edu/etd

\section{Recommended Citation}

Branch, Ronald A. II, "Leadership Practices of a Principal in a High School with a High Teacher Retention Rate" (2013). Graduate Theses, Dissertations, and Problem Reports. 3631.

https://researchrepository.wvu.edu/etd/3631

This Dissertation is protected by copyright and/or related rights. It has been brought to you by the The Research Repository @ WVU with permission from the rights-holder(s). You are free to use this Dissertation in any way that is permitted by the copyright and related rights legislation that applies to your use. For other uses you must obtain permission from the rights-holder(s) directly, unless additional rights are indicated by a Creative Commons license in the record and/ or on the work itself. This Dissertation has been accepted for inclusion in WVU Graduate Theses, Dissertations, and Problem Reports collection by an authorized administrator of The Research Repository @ WVU.

For more information, please contact researchrepository@mail.wvu.edu. 
Leadership Practices of a Principal in a High School with a High Teacher Retention Rate

Ronald A. Branch II

Dissertation submitted to the College of Education and Human Services

at West Virginia University in partial fulfillment of the requirements

for the degree of

Doctor of Education

in

Educational Leadership Studies

Dr. Paul Chapman, Ph. D., Committee Chair

Dr. Jerry Jones, Ed. D.

Dr. Micah Fierstein, Ed. D.

Dr. Reagan Curtis, Ph. D.

Dr. G. Ronald Brown, Ed. D.

Department of Curriculum \& Instruction/Literacy Studies

Morgantown, West Virginia

2013

Keywords: collegiality; familial culture; Leadership Practices Inventory; organizational culture; school culture; school leadership; teacher attrition; teacher retention

Copyright 2013 Ronald A. Branch II 


\section{ABSTRACT \\ Leadership Practices of a Principal in a High School with a High Teacher Retention Rate Ronald A. Branch II}

As political and societal expectations for our nation's public school system continue to increase, leaders of local school systems are ever mindful of the demands for continual improvement. The cornerstone for this improvement is the classroom teacher. Research has supported the idea that teacher experience is influential in the effectiveness of the teacher. The statistics on teacher attrition, though, are disheartening.

The purpose for this research is to uncover emerging themes regarding the leadership practices and cultural elements that are in place in a school that has a high retention rate of teachers. This case study includes a school in the eastern panhandle of West Virginia. This school has been identified as having the highest teacher retention rate in its programmatic level in Berkeley County, West Virginia, and has one of the highest retention rates among all programmatic levels in the county. Through the use of the Leadership Practices Inventory (LPI) designed by Kouzes and Posner (2003), open-ended interviews, and a review of school documents, the researcher provides data relevant to the creation of a school culture that fosters teacher retention.

This study describes the elements found in this high school that have led to the retentive culture which exists. The familial culture of this school has been affected by the leadership practices of the principal, the collegiality and friendships among the staff, and the attitudes and behavior of the students. These leadership practices and cultural elements are described in detail in order to provide an understanding of components of a school culture that leads to teacher retention. 


\section{Table of Contents}

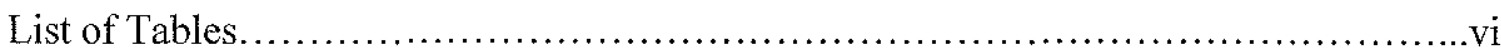

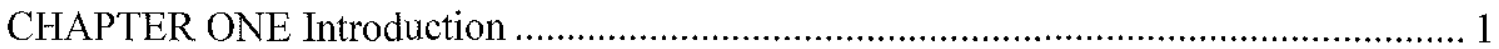

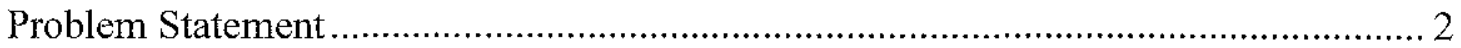

Professional Significance and Purpose of the Study ................................................. 5

Overview of the Method and Research Questions............................................. 6

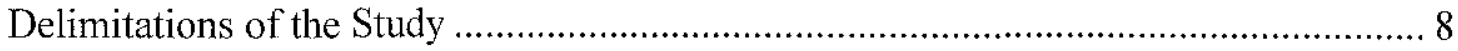

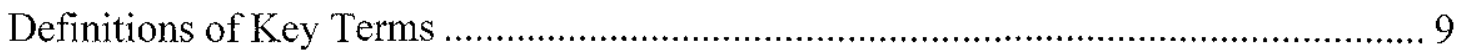

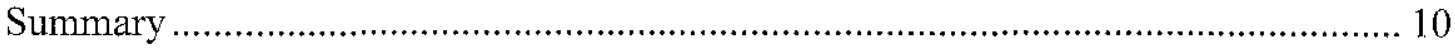

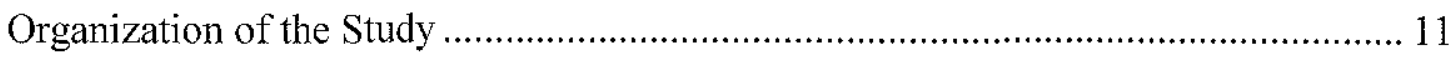

CHAPTER TWO Review of Related Literature ......................................................... 12

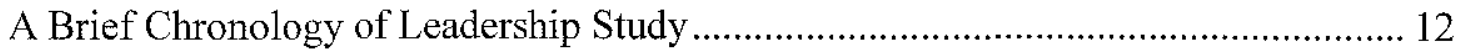

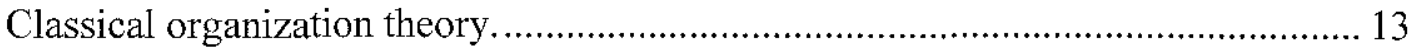

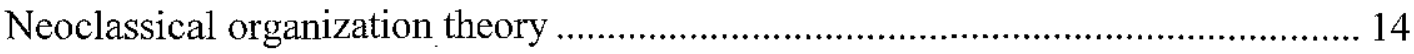

Human relations and neo-human relations theories........................................ 16

Characteristics of Transformational Leadership .................................................. 18

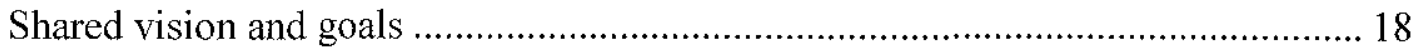

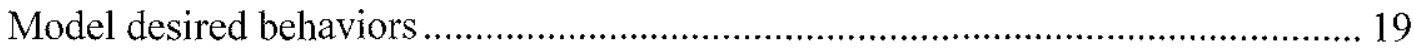

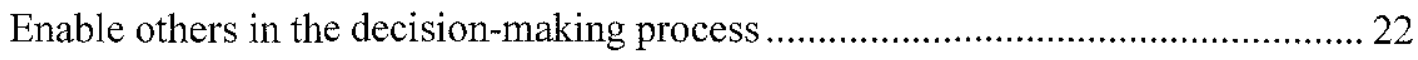

Motivation and persuasion: Authority, power, and the work environment ............. 23

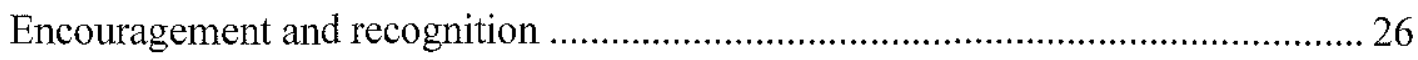

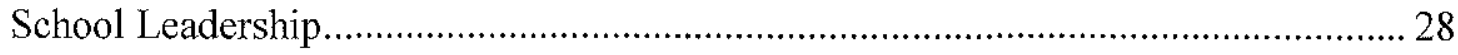

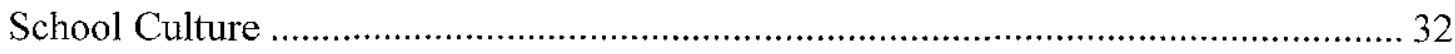




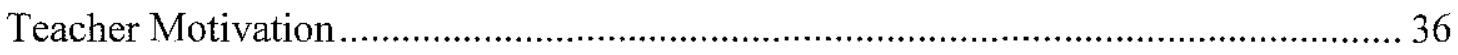

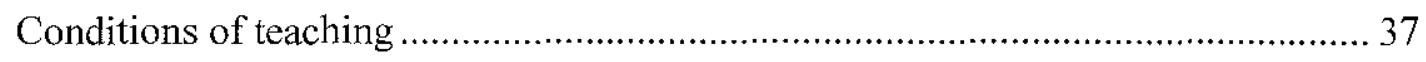

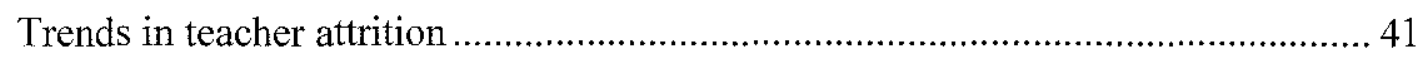

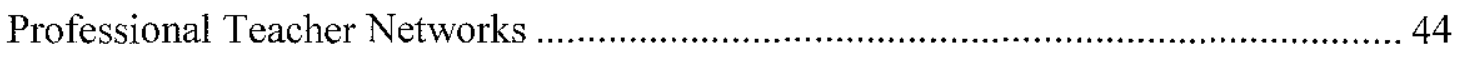

Recent Research in the Creation of a Retentive Culture...............................................4 46

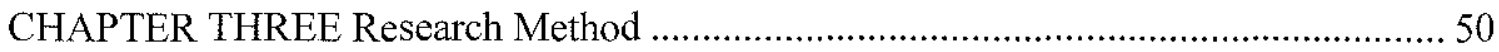

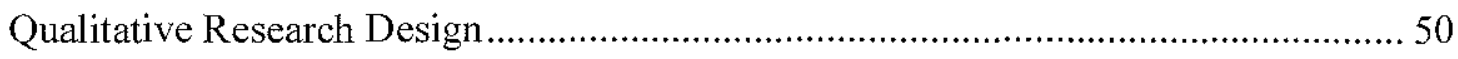

Retentive Cultures from a Qualitative Perspective ....................................................52

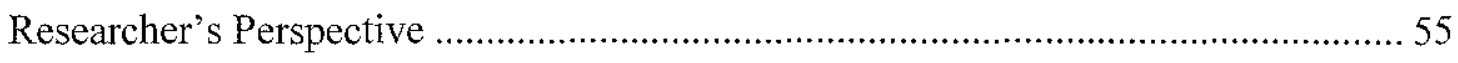

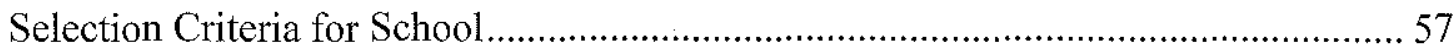

Characteristics of the Research Site and Participants................................................. 58

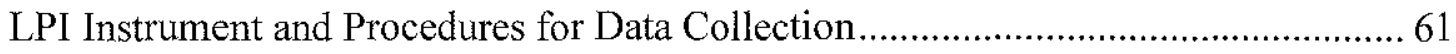

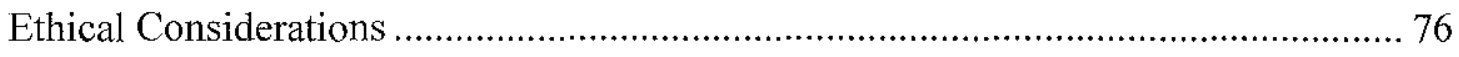

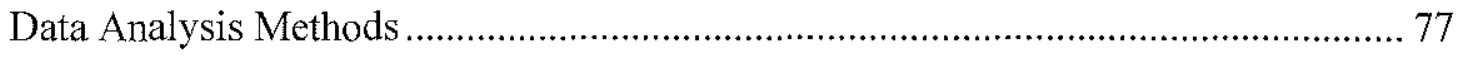

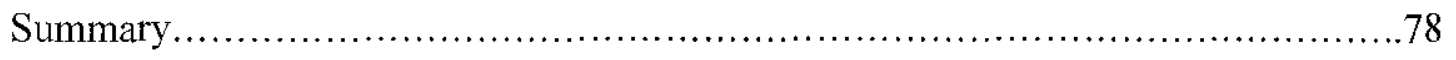

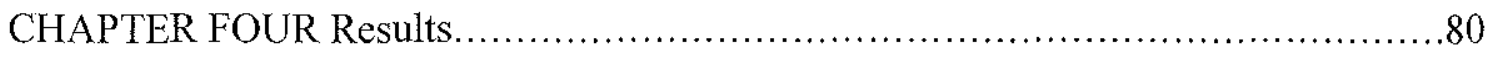

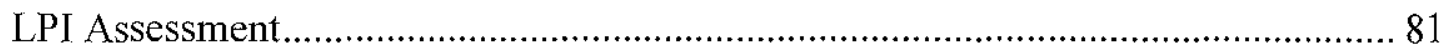

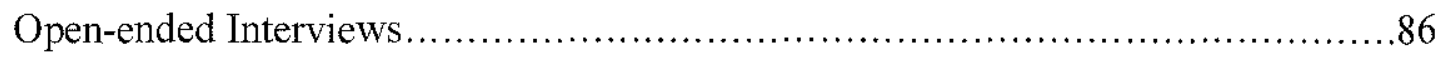

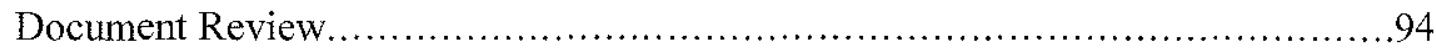

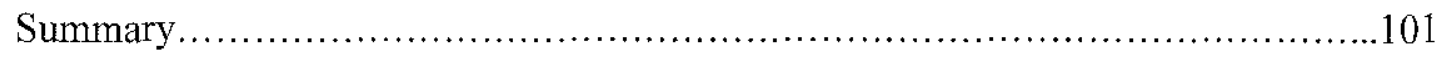

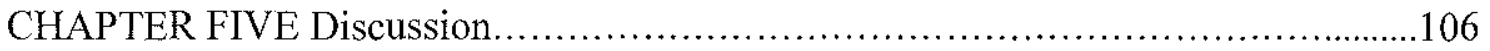

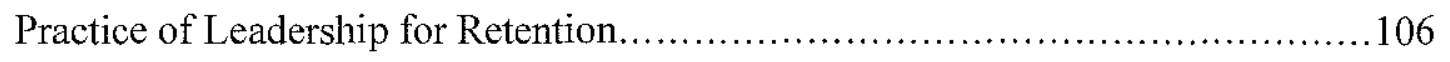

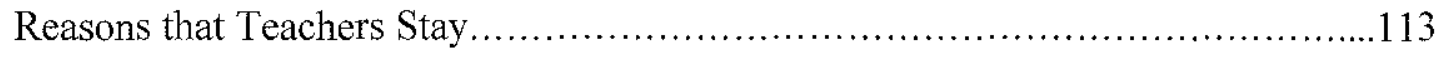




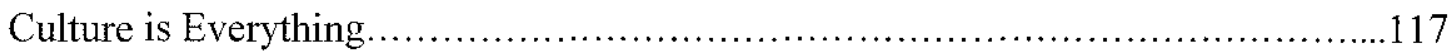

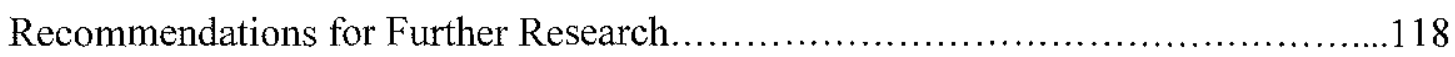

References.................................................................. 121

Appendix A Request for School Participation...........................................134

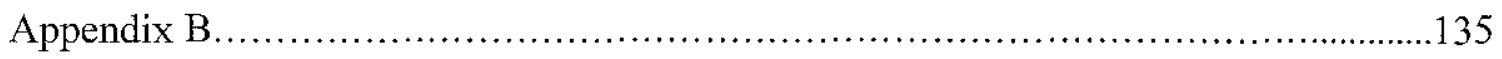

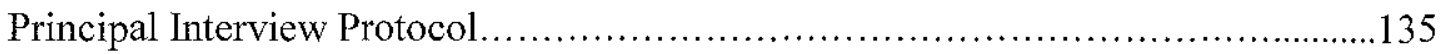

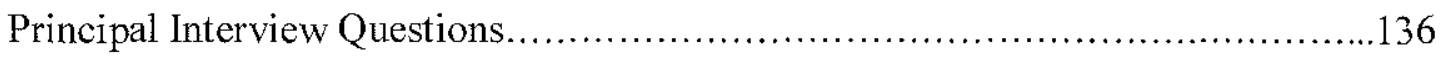

Appendix C Request for Staff Member Participation...............................138

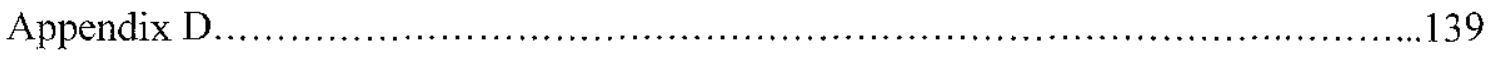

Staff Member Interview Protocol ............................................ 139

Staff Member Interview Questions......................................... 140

Appendix E Request for County Administrator Participation........................143

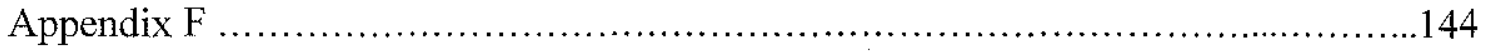

County Administrator Interview Protocol.....................................144

County Administrator Interview Questions................................ 145 


\section{List of Tables}

Table 1 Selection Criteria for School Participation in Leadership for Teacher

Retention

Table 2 Distribution of Interview Questions for Leadership for Teacher Retention using Patton's (2002) Question Types Across Participants - Question 1 .66

Table 3 Distribution of Interview Questions for Leadership for Teacher Retention using Patton's (2002) Question Types Across Participants - Question 2 70

Table 4 Distribution of Interview Questions for Leadership for Teacher Retention using Patton's (2002) Question Types Across Participants - Question 3 ............73

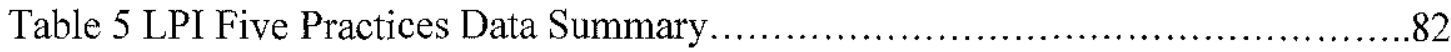

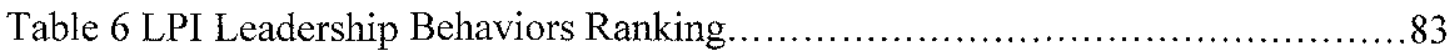

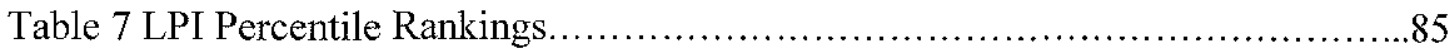

Table 8 Open-ended Interviews Emergent Themes....................................102

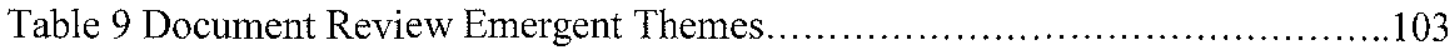

Table 10 Thematic Overlap Between Qualitative Data and LPI Results................104 


\section{Chapter One: Introduction}

The position of professional educator has historically carried significant esteem and respect within local communities. The opportunity to positively affect the lives of young learners, thereby influencing the nature of the surrounding community, has lured many talented, intelligent individuals into the field of teaching. Vivacious, enthusiastic college graduates fill positions in classrooms across the nation; excited about their futures in the schoolhouse and determined to influence the children and youth of America in a manner that will improve the quality of the lives touched during their tenure.

Unfortunately, the optimism felt by so many of these young teachers is short lived. A recent survey conducted for MetLife (2012) found that only $39 \%$ of teachers are currently satisfied in their jobs, and over half of the teachers surveyed stated that they feel stressed several days a week due to their teaching positions. It has been found that that one-third of teachers leave the profession within the first three years of teaching (Fulton, Brown, \& Goldenberg, 2005). Following the 2008 academic year, the United States Department of Education (2010) found that over 527,000 teachers transferred schools or left the profession of education. Weld (1998) also cites a 1970's study of Michigan teachers which determined that only $56 \%$ were still in the classroom after six years, demonstrating that the problem of teacher retention is not new to the field of education.

It is both astonishing and disparaging to consider the teacher turnover rate that schools experience. "High rates of teacher turnover diminish teaching quality; drive a cycle of constant teacher shortages; and ultimately undermine the community, cohesiveness, and continuity essential for school effectiveness" (Fulton et al., 2005, p. 299). This flow of educators in and out of the school further complicates the already 
difficult job of building-level administrators as they attempt to optimize the educational experience of the students in their care. Providing mentorship and training for new teachers takes away from other managerial, instructional, and leadership roles that administrators must deal with on a daily basis.

As teachers gain experience, the opportunity for professional growth and an increase in effectiveness are often the result. Ingersoll (2012), though, cites national statistics demonstrating that between 1988 and 2008 the number of first year teachers tripled, causing a trend that he describes as the greening of the teacher force. Ultimately, the concern for the well-being of the students should drive the study and development of programs that will optimize the retention of a highly motivated and highly qualified faculty.

\section{Problem Statement}

Evidence lends credence to the fact that there is a nation-wide dilemma in terms of keeping classroom teachers in education. Concerning the maintenance of highlyqualified personnel in our nation's classrooms, the dilemma is not too few teachers coming into the profession, but an abundance of teachers leaving the field of education creating an astounding teacher turnover and attrition rate (National Commission on Teaching and America's Future, 2002). Statistics from the symposium cited above demonstrate that, in 1999, our nation's school systems hired 232,000 teachers who had not been in the classroom the year before, and lost 287,000 teachers who left to pursue careers in a different profession. Haberman and Rickards (1990) have determined that nearly one-half of teachers, nationally, quit within the first six years. 
An executive summary produced by the West Virginia Department of Education (2007) highlighted the fact that in five of the seven identified high need content areas, the number of teacher postings in the state of West Virginia exceeded the amount of certifiable graduates in these areas from West Virginia institutions of higher education. This disparity, among other conditions related to public education, has led to the fact that ten percent of West Virginia classrooms in both the 2005-2006 and 2006-2007 school years were not filled with a certified teacher. Furthering the complexity of this issue is the fact that many West Virginia teachers are already eligible for retirement, and 788 teachers retired prior to the 2008-2009 school year (West Virginia Department of Education, 2009). In the counties of Berkeley and Jefferson, in the Eastern Panhandle of West Virginia, the percentage of teachers eligible to retire is far lower than the state average. The percentage of teachers with three or fewer years of experience, though, is almost double that of the state percentage and the number of permanent substitutes who are hired to fill long term positions is far greater than the state average (Professional Personnel Data Report, 2009). This lack of experienced teachers is caused, in part, by the exodus of teachers to neighboring states that offer more attractive pay packages for educators. This report also shows that each county in the Eastern Panhandle, including Morgan, is far below the state average of $59 \%$ of teachers who hold a permanent certificate. Forty-one percent of Berkeley County teachers, $42 \%$ of Jefferson County teachers, and 39\% of Morgan County teachers hold a permanent certificate.

Nationally, school systems will have to hire at least 2 million new teachers within the next decade to compensate for increased student enrollment, in conjunction with teacher turnover and retirement (Budig, 2006). At the local level, the problem with 
teacher retention is exacerbated by higher pay scales in neighboring states and a higher cost of living than other areas within the state of West Virginia. Musselman High School in Berkeley County, for instance, has replaced over two-thirds of classroom positions (a total of 66) in a four year time period.

The constant turnover and attrition of teachers creates problems in district governance, building level administration, and, most importantly, in sustaining a high level of education for the students in every classroom. It is not surprising that research has "identified the inextricable links between the quality of teaching and the achievement of students" (Berry, 2005, p. 290). The staggering turnover rate of classroom teachers leaves school administrators struggling, on a yearly basis, to fill positions; often creating dire circumstances in which quality teaching is sacrificed in order to fill positions for which there are no qualified applicants (National Commission on Teaching and America's Future, 2002).

As teachers mature and gain experience, undoubtedly, their performance in the classroom is impacted. Teachers who have less than three years of experience are often found to be less effective than more experienced educators (National Commission on Teaching and America's Future, 2002). While research has been conducted in order to reveal the reasons that teachers are exiting the classroom, there has been little research into the school leadership practices and cultural elements that cause teachers to stay in their current positions. As accountability for local schools remains a focus in the realms of government and public concern, the challenge to improve the reliability and sustainability of the public school faculty, and create a culture of retention within the walls of the local school is a priority. 


\section{Professional Significance and Purpose of the Study}

There are many factors that may influence teacher hiring and retention that are beyond the realm of influence of the local school administrator. State legislatures and governors, state superintendents and boards of education, as well as the state department of education can propose, influence, and create policies that may positively or negatively affect teachers' desires to remain committed to the education profession. Most of these policies and procedures are beyond the scope of influence that a building level administrator maintains. The purpose of this study is to identify the emerging themes that may be affected by school building principals that create a retentive culture within a school building.

Extensive studies, some of which will be discussed in this paper, have been conducted to determine why teachers, in various educational environments and types of communities, are leaving the profession. While these results reveal the negative aspects within the institution of education, and bring to the forefront the disparities among other professional fields which drive teachers to other occupations, this study brings to light positive cultural and leadership characteristics within schools that influence teachers, creating the desire to remain in their current positions. The qualities identified could lead to the construction of professional development opportunities for teachers and administrators, positive school wide cultural traditions, instructional leadership criteria for building level administrators, and communication strategies that will assist administrators in the creation of a retentive culture at the local school level.

The emerging themes in the area of teacher retention are crucial to all of those involved in the local school system. Teachers need an environment that is conducive to 
their own professional development, and that assists in the establishment of a school and class environment that is supportive of their professional needs. Students will find that their own educational objectives are more easily attained in a school that provides a secure, retentive culture among faculty members. Parents will feel more secure in the future of their own children, as the students become more fully prepared for life beyond their public schooling. Finally, central office personnel will be required to deal with fewer issues from schools that have an established tradition of maintaining experienced, capable educators. The researcher has found that it is much easier to create a positive environment for learning when a faculty is retained over time. Teacher retention is a key in the establishment of an educational coalition that involves members of both the internal and external communities of the local school.

\section{Overview of the Method and Research Questions}

The research questions stem from the desire to search out those conditions found within a school, especially in the area of building-level leadership, which result in a retentive culture among the faculty and staff. This research provides a framework by which a building level administrator, independent of state and district level leadership, influences the necessary components of a positive school culture that promotes teacher retention.

The research questions for this study are:

RQ1. What are the leadership practices of a principal in a selected high school that has a high teacher retention rate in a region of West Virginia?

RQ2. Why do teachers stay in a selected high school that has a high teacher retention rate in a region of West Virginia? 
RQ3. What contributes to a school culture that retains teachers in a selected high school that has a high teacher retention rate in a region of West Virginia? The proposed research is a case study of a selected high school that has demonstrated the highest retention rate among faculty members in the eastern panhandle of the state. The school to be examined in this case study was selected using the concept of an extreme case. Such selection is based on the determination of a particularly successful example of the case to be studied (Flick, 1998). This instrumental research study focused on the characteristics of a school and a school's leadership, as reflected in the selected school, which positively affect the teacher retention rate. The research was conducted from the perspective of interpretive inquiry, as the evidence of the everyday social life within the school walls was examined in a method that sought to ensure an objective study of the school (Soltis, 1984).

The Leadership Practices Inventory (LPI), specifically the 360-degree leadership assessment instrument, created by Kouzes and Posner (2003), was used to collect quantitative data regarding the perceived leadership practices and ability of the principal of the selected school. The 360-degree model provided the opportunity to collect data from the principal, as well as, members of the central office, and faculty. An instrumental case was chosen in order to shed light on, and provide understanding of a given phenomena (Stake, 1995), which in this instance is a high rate of teacher retention. Qualitative data was also collected using a single in-depth interview of each participant, the maintenance of a researcher $\log$, and the review of a cache of school documents, including memos, notes, and announcements. 
The findings of this study provide an accurate representation of the leadership ability of the principal, and the culture of the school that was selected. A complete description of the research methods for this study is detailed in chapter three of this document.

\section{Delimitations of the Study}

Due to the fact that this research is a case study, there are limitations to the applications of the emerging themes, and certain areas in which the findings are not relevant. This research reflects an instrumental case study of the high rate of teacher retention in this school. By definition, a case study is an exploration of a bounded system, as the sample is bounded by place and time (Creswell, 1998).

Because the school selected as the sample for this research was chosen as an extreme case of teacher retention, the findings are indicative of the leadership and culture within this school only. The school selected has been determined to have a high teacher retention rate in comparison to other schools in the immediate region of the state.

One high school was selected for this case study, which is located in the eastern panhandle of West Virginia. Reports generated by the West Virginia State Board of Education demonstrate that schools in this area of the state have more difficulty retaining teachers than other geographical regions, and are forced to hire a greater number of uncertified personnel in order to fill teaching positions, as these school systems must compete with neighboring states that offer better financial packages for educators (Professional Personnel Data Report, 2006). Due to the location of this study, and the difficulties evident in attaining and retaining highly qualified teachers during the time period that the study was conducted, the results may not be applicable to other areas 
within the state, or to the school systems in other states. Because this is an instrumental case study, though, extrapolations from the results may be applicable to other situations under similar conditions (Patton, 2002). The findings of this study may be transferable to schools that operate under similar circumstances to those found in this school.

This study provided only a snapshot of this phenomenon at the time of the conducted research. This fact must be noted as economic and political conditions are key determinants in attrition rates of teachers, and these conditions may change in a brief period of time.

Participation of personnel associated with the selected school in the survey and interview process was voluntary. Therefore, it is possible that not all perspectives and opinions were elicited.

Due to the constraints previously mentioned, there is transferability to only those schools that operate under similar conditions to the school selected for this study. Leadership qualities of the principal and cultural elements of the school are reflective of this school only, and may not be projected onto other schools or school systems that do not face the challenges evident in this system of schools.

\section{Definitions of Key Terms}

Leadership practices: the patterns of action employed by a school leader to accomplish the stated goals of the school in which the leader is employed.

Local school leader: a school-level principal, assistant principal, or dean of students within a school that is not considered to be positioned at the district, state, or national level. 
School culture: A pattern of shared basic assumptions that the [school] learned as it solved its problems of external adaptation and internal integration, that has worked well enough to be considered valid and, therefore, to be taught to new members as the correct way to perceive, think, and feel in relation to those problems (Schein, 1993, p. 364-365).

Teacher appreciation: the celebration of teacher accomplishment and dedication separate from the emotional regard of the faculty.

Teacher Attrition: the loss of teachers from a school system due to retirement or resignation to pursue careers in other educational settings or non-educational professions.

Teacher motivation: the desire within a teacher to employ techniques and strategies, and exert the required energy and time to assure learning for all students within the realm of the school.

Teacher network: a group of teachers working together in a professional capacity to attain the goal of educating all students.

\section{Summary}

While a certain percentage of teacher turnover is expected, and in some cases beneficial, it is undoubtedly helpful to building-level administrators to maintain the majority of the school's faculty. As expectations for student output increase and public education undergoes more thorough scrutiny by the community and the government, enthusiasm and experience of school teachers will be commodities that local administrators strive to secure.

While there are many aspects affecting teacher retention that building-level administrators cannot control, the creation of a retentive culture within the building can 
provide great means for maintaining solidarity among a school's faculty. Principals, assistant principals, deans, and even superintendents and board office personnel can take steps to creating such a culture amongst the staff that they oversee within the local school building. This study was designed to outline those leadership qualities and cultural norms that aid building level administrators in creating a retentive culture within the local school building.

\section{Organization of the Study}

The remainder of this study is organized into five chapters, references and relevant appendices. Chapter Two presents a review of literature related to pertinent issues in the following categories: (a) the chronology of leadership study, (b) practices of transformational leadership, (c) school leadership, (d) school culture, (e) teacher motivation, $(\mathrm{f})$ teacher networks, and $(\mathrm{g})$ recent research in the area of creating a retentive culture. Each of these topics is considered appropriate to the creation of a school climate that fosters teacher retention. Chapter Three reveals the research design and appropriate methods for conducting this case study. The research instrument is discussed and methods for attaining relevant qualitative data are revealed. The selection of the sample is also discussed in this chapter. Chapter Four presents the results of the LPI survey, open-ended interviews, and the review of relevant documents. The emerging themes relevant to the leadership practices and cultural elements of this school, which maintains a high rate of teacher retention, are detailed. Finally, Chapter Five includes a discussion of the researcher's thoughts and experiences, as well as the implications of the study on the field of education, and recommendations for further research. 


\section{Chapter Two: Review of Related Literature}

Following is a review and synthesis of related literature and research studies relevant to the investigation of leadership practices and cultural conditions within a public school building that lead to a prolonged commitment by the faculty. This literature review reveals problems, issues, and the conditions of schooling within modern education, as perceived by classroom teachers, which influence them to either leave or continue in the public school system. Furthermore, positive elements of organizational culture and transformational leadership characteristics are studied in order to provide a foundation for uncovering the necessary components to forming a retentive culture among members of a public school faculty and staff. This chapter focuses on pertinent issues in the following categories: (a) the chronology of leadership study, (b) practices of transformational leadership, (c) school leadership, (d) school culture, (e) teacher motivation, (f) teacher networks, and $(\mathrm{g})$ recent research in the area of creating a retentive culture. Evidence suggests that competent leaders, who have knowledge in the philosophies and practices discussed in the following sections, should be able to transform their expertise into skills that create a retentive culture among their followers.

\section{A Brief Chronology of Leadership Study}

Leadership theory has deep roots in the mass of organizational research and theory by which it was preceded. Organizational theory established its roots as early as Old Testament biblical times, and early beliefs on organization and leadership are promoted in the writings of many famed philosophers such as Socrates, Aristotle, and Machiavelli, as well as the works of literature found in many established religions. The study of leadership from a research perspective, though, is an initiative that began around 
the turn of the twentieth century. Bailey (1991) provides a very simplistic definition of leadership: the power to accomplish. Schlechty (2001) further states that leadership involves the ability to recruit followers and to ascertain their devotion toward common goals. While on the surface leadership may not sound complicated, a plethora of essential characteristics underlie the ability to motivate a group of people to work together toward a shared vision and set of common objectives. Ultimately, a great leader will be able "to make human strength effective and human weakness irrelevant" (Drucker, 1999, p. 7). Toward this cause, there is a great deal of effort which must be devoted.

Classical organization theory. Early studies in the area of leadership placed a great deal of focus on military leaders and their conquests over forces that were deemed to be superior in military prowess. Research in leadership during the early 1900's was focused primarily on the personality of the leader, as well as the traits and behaviors that they displayed (Fiedler, 1996). These trait theories, which abounded during the age of the classical organization theorists, began with the assumption that there were specific personal traits that allowed a person to become an effective leader, and sought to identify the qualities that differentiated leaders from followers (Allen, 1998).

According to the classical organization theories of the early $20^{\text {th }}$ century, the concept of organizational leadership was viewed primarily from the standpoint of management, and workers were deemed "not as individuals but as interchangeable parts in an industrial machine" (Shafritz, Ott, \& Jang, 2005, p. 29). During this era, Henri Fayol, a French engineer, developed the first comprehensive theory on management (Shafritz et al.). According to Fayol's principles of management, an establishment was 
best served by a system in which there was one definitive leader and a scalar chain of authority. Workers should be specialized in one area and were to submit themselves to their superiors and to the general interests of the organization (Fayol, 1916). Taylor (1916) established the concept of scientific management at this time, which also promoted the idea of specialization on the side of workers. Taylor believed that managers, for the good of the organization, should willingly undertake "the new and almost unheard-of burdens" which he outlined under his ideals of scientific management (p. 65). The principles of scientific management which were outlined by Taylor included: (a) the gathering and reduction of the knowledge traditionally held by the workers; (b) the scientific selection, observation, training, and proper payment of the workers; (c) requiring workers to employ the scientific measures found to increase production, both through humanitarian and forceful means; and (d) the division of work into managerial and workmen duties. Taylor was convinced that each duty of the workers should be preceded by an aspect of managerial planning. Founded on the belief that "...organizations should be based on universally applicable scientific principles ..." (Shafritz et al., 2005, p. 88), the classical era of organizational theory had a resounding affect on managers and leaders in the early 1900's. Due to a lack of empirical evidence, though, classical theories were soon to be challenged as researchers continued to delve into the science of leadership and management.

Neoclassical organization theory. As leadership research progressed, it became apparent that basing a leader's effectiveness on innate personal traits was inappropriate. Studies conducted in the early 1900 's found that there was no single trait, or combination of traits, that fully explained the success of great leaders (Southwest Educational 
Development Laboratory, 1992). During the 1930 's, 40's and 50's, neoclassical theorists challenged and extended many of the precepts condoned throughout the classical age. In 1939, psychologist Kurt Lewin and a group of fellow researchers conducted a study in which three different styles of leadership were identified: autocratic, laissez-faire, and democratic (Van Wagner, 2008). Autocratic leaders incorporate little or no input from followers in the decision-making process, and progress through the role of leadership from a dictatorial standpoint. Laissez-faire, or delegative, leaders offer little guidance, and rely on the group to make decisions. The strategy that was deemed to be the most effective by Lewin was democratic leadership. These types of leaders play an active role in decision-making, while allowing group participation. The democratic style of leadership engages members of the group, creating an environment in which motivation and creativity are maximized. Lewin's research set the cornerstone for future studies that examined the roles that leaders played and the skills that they demonstrated; furthering the examination of leaders beyond simple inherent characteristics.

Barnard (1938) was one of the first theorists to propose a cooperative system of organization in which it is essential for leaders to ascertain the willing cooperation of those employed by a business. Barnard believed that the "inculcation in the real existence of a common [organizational] purpose" was essential (p. 87), and supposed that leaders should employ both incentives and persuasion in order to garner support from the workers toward the attainment of this purpose.

While neoclassical organization theories did not have the substance to replace the classical school of thought, theories established during this era played an important role in the extension of organizational research (Shafritz et al., 2005). Shafritz et al. point out 
that the intellectual and empirical approaches of these theorists expand the simple, mechanical mold to which organization theory had been previously held. Though a strong base had been established through the research and writing of the classical and neoclassical eras, further investigation into the roles of leaders within an organization has expounded upon established principles and discovered new strategies and roles of the modern leader.

Human relations and neo-human relations theories. Much of the current practice in leadership lends itself to the findings of the research conducted in human relations beginning in the late 1950 's. The study of human relations was introduced by a group of Harvard researchers who initially intended to examine the effects of physical factors on laborers. This research, known as the Hawthorne Experiments, provided insight into the human factor of management as laborers seemed to respond more to personal attention than to the physical conditions of their work and workplace. These researchers found that it is impossible to understand a worker without consideration of their feelings and sentiments (Roethlisberger, 1941).

Maslow (1943) took the evidence found in the Hawthorne Experiments a step further by establishing a pyramid of human needs that must be addressed by organizational leaders. According to Maslow's hierarchy, people progress through a stratification of physiological, safety, love, and esteem needs before they are able to reach the level of self-actualization. While addressing the needs portrayed by Maslow, McGregor (1957) formulated the belief that management cannot meet people's needs; thereby motivating them, by exercising control over workers. Instead, management's core concern should be the alignment of organizational processes which allow their 
workers to meet their own goals by working toward the goals of the organization. McGregor's "Theory Y" is defined by "a process primarily of creating opportunities, releasing potential, removing obstacles, encouraging growth, [and] providing guidance" (p. 183).

Past research in the areas of organizational and leadership theory provide a knowledge base of experience and philosophy from which modern leaders can learn and grow. While evidence from the human relations and neo-human relations researchers suggests that leaders create a retentive culture through personalization and the ability to address the needs of their workers, many practices that were popular among classical and neo-classical theorists are relevant to the creation of a positive work environment as well. Through the examination of the researchers in each of these eras, a modern leader can establish those practices which allow them to form an organizational structure that meets the needs of both the organization and each individual; thus, creating a retentive culture among their staff.

In 1978, Burns introduced the theory of transformational leadership into the mainstream of leadership research. According to Burns (as cited in Syque, 2008, para. 2) a transformational leader engages in the process of raising both group members and the leader "to higher levels of morality and motivation." Transformational theories, known also as relationship theories, still remain at the forefront of the study of leadership. These types of leaders are able to motivate and inspire their followers by creating a sense that maximizing individual potential is important, but maintaining the good of the entire group is paramount (Van Wagner, 2008). A transformational leader is able to instill "feelings of confidence, admiration, and commitment in [his or her] followers" (Allen, 
1998, para. 43). In order for a leader to proceed in a transformational role, and maximize the potential of the group, there are several steps that must be taken.

\section{Characteristics of Transformational Leadership}

Transformational leadership consists of tactics that promote motivation and morality in both leaders and followers. Kouzes and Posner (2007) describe transformational leaders as those who can persuade others to put forth their energy into those strategies that benefit the organization. Transformational leaders are certainly focused on the achievement of the group, but are also concerned that each group member fulfills his or her own potential (Van Wagner, 2008). While transformational leaders are found in numerous settings and occupations, there are five practices common to this type of leader which have been consistently identified throughout this literature review: (a) the creation of a shared vision and goals, (b) modeling of desired behaviors, (c) the enablement of others in the decision-making process, (d) proper use of motivation and persuasion techniques, and (e) encouragement and recognition of success.

Shared vision and goals. The first practice that one must employ to become a dynamic transformational leader is to inspire a shared vision and goals that the organization is to work toward. The vision of an organization should reflect its fundamental reason for existence, should demonstrate the unchanging core values, and display the aspirations of the organization for the future (Collins, 1999). The leader must set the tone, letting other members of the organization know what is expected individually, and where the organization, as a whole, is directed. Transformational leaders will "envision the future by imagining exciting and ennobling possibilities ... while enlist[ing] others in their dreams by appealing to shared aspirations" (Kouzes \& 
Posner, 2003, p. 5). A lack of a shared vision often causes distrust among individuals; therefore, a leader must be certain to communicate this vision and organizational objectives in a clear manner, and ensure that the group members are certain about the organization's expectations of them and intentions for progress (Schlecthy, 2001). Failure to clearly articulate the vision among staff members will most likely result in the loss of the vision (Speck, 1999). The vision should be used to unite employees in a commonality of purpose, while the objectives can be used as stepping stones toward reaching organizational success. It should always remain a priority for organizational leaders to ensure that members of the organization "maintain a clear focus on the future and [remain] constant on their pursuit of goals" (Schlechty, p. 166). According to Fayol, "union [within an organization] is strength" (1916, p. 59). By engraining devotion toward an organizational vision and common objectives, a leader can direct the energy and focus of all members of the organization, and better ensure the success of the organization.

Model desired behaviors. Positive transformational leaders must also model the behaviors desired from one's employees. While such modeling is certainly important in order to move toward the shared vision and goals of the organization, this aspect of leadership also is important to attain a foundation of trust and credibility among others within the organization. Fleck (2005) stresses the importance for the leader to be a positive role model in order to set the tone for others to follow. While a leader may not always be liked, it is imperative that they earn the respect of others by presenting the attitudes, beliefs, and actions that are expected from their constituents (Drucker, 1999). The demonstration of a commitment to the actions of the organization, and follow- 
through on stated goals, will allow a leader to establish a foundation of trust that is irreplaceable when attempting to lead others within an institution (Speck, 1999). Kouzes and Posner (2003) assert that in order to build such credibility and trust among one's followers, a leader must both say and do those things that they intend to model.

The first component to modeling desired behaviors is to be able to effectively say, or communicate, what is expected. Zhou (n.d.) relates that Chester Barnard described functions of leaders to include the creation of a communication system within the organization. Dance (1988) defines three levels of communication: intra-personal, interpersonal, and person-to-person. Intra-personal communication involves reflection and talking to oneself. While this type of communication is certainly important, interpersonal and person-to-person communication are the two levels that should be accentuated in a leader. Both of these levels involve communicating with other individuals, but differ in the terms or source of the communication; interpersonal communication is approached in terms of differences while person-to-person involves group commonalities (Dance). "Employees have a deep-rooted need to be informed about what's happening at all levels of their organization ..." (Nelson, 1999, p. 268). A leader who wishes to effectively operate an organization should be adept with both interpersonal and person-to-person communication in order to assure that organization members remain up-to-date on organizational status and expectations.

Communication can involve a variety of types of interactions. Fleck (2005) emphasizes the need for both formal and informal conversations with employees. Large group or department assemblies can be used to formally communicate issues among a set of individuals, as can one-on-one or small group meetings. Concurrently, informal 
conversations can be used to monitor daily progress and allow opportunities for employees to convey interests and concerns in a non-threatening environment. Fleck further states that written communication should be used in conjunction with verbal in order to maximize the retention of important messages. The engagement of multiple senses while communicating can augment the ability of the leader to effectively convey the desired message. Memorandums, bulletins, notes, posters, and e-mails all provide the opportunity for the leader to express written communication throughout the organization. Through the proper and effective use of communication, a leader can assure that employees are thoroughly informed, meeting expectations, and are experiencing a positive work environment.

The second aspect of modeling by a leader is comprised in the action, or doing, of desired behaviors. A leader must be willing to wholly commit to the shared vision and goals that have been established within the organization; therefore, becoming a living example of these components. Saphier (2005) writes that leaders must model through visible actions which will be noticed by those within an institution. Leaders should align their personal actions with the shared values of the organization (Kouzes and Posner, 2003). By carrying out those actions that represent the vision and goals of the organization, a leader will be able to engage the conviction of his or her followers.

The goal of modeling desired behaviors through communication and action is to build trust and credibility among the members of one's organization. Followers will only commit themselves to the behaviors that the leader is courageous enough to instill within their own routine. In order to build upon the shared vision and goals that have been 
established within an organization, the leader must be willing to demonstrate such commitment.

Enable others in the decision-making process. Transformational leaders will find methods to involve employees in the decision making process and to create leadership opportunities for members of the organization. While this action may seem to demean the authority of the leader, Bailey (1991) states that there is actually "no power equal to sharing the responsibility with other professionals, training them to take responsibility, developing them to be independent, and watching [them] grow" (p. 42). Leaders who are able to foster collaboration and reciprocity can "strengthen others by increasing self-determination and developing competence" (Kouzes and Posner, 2003, p. $5)$.

It should be a priority for leaders to train subordinates to think and react like themselves (Fleck, 2005). In fact, an environment in which participation is maximized reduces the need for centralized control (Kelleher, 1999), freeing management to focus on other issues that will improve productivity. Schlechty (2001) argues that it is a fundamental task for those in authority to engage in shared leadership, participatory management, and member empowerment. The bond among team members and sense of ownership that is created through shared decision making can lead to great successes, both individually and within the organization. Conversely, "stakeholders who are left out of the process will be less committed to the [organization's] mission and may in fact erect barriers" that reduce the effectiveness of the organization (Lezotte \& McKee, 2002, p. 129). Bailey (1991), therefore, surmises that the true secret to great organizational accomplishment is the extension of participation throughout the entirety of the 
organization, and that by fully disclosing information and sharing expertise with all involved, a leader can create the power to influence those who are engaged in the decision making process.

\section{Motivation and persuasion: Authority, power, and the work environment.}

Another essential practice of an effective transformational leader incorporates motivation and persuasion. In the effort to drive a group of individuals toward unity and organizational success it will be necessary to rely upon those leadership skills needed to encourage all involved to prioritize the needs of others, and the organization in general. While creating a shared vision, instilling proper lines of communication, and providing leadership and input opportunities, as previously discussed, all play a role in this area, there are other indispensable elements required to effectively motivate and persuade group members to perform at an optimal level.

Schlechty (2001) defines power and authority to be primary elements available to leaders in the effort to maximize the motivation of their staff. There is a marked difference in the definition of these two elements and the appropriate circumstances in which they may be employed. A successful transformational leader must have access to, and be able to employ, both authority and power within the sphere of their influence.

Authority, often a misunderstood concept in the realm of leadership, is simply the right to give orders (Fayol, 1916). Hoy and Miskel (2005) describe several circumstances of authority in which leaders may find themselves. Charismatic authority is dependent on the virtue of the leader and the trust created among organization members for the leader. Traditional authority is rooted in the belief that the leadership position holds a sanctity that allows for the creation and dissemination of orders. This 
type of authority is established based on the customs of the organization and accompanying norms and values. Finally, legal authority is granted based on a set of laws or rules governing those within the given organization. Authority in each of these conditions is a unique leadership asset as it is granted by those in subordinate positions, due to the contingency of their acceptance of the leader's orders (Zhou, n.d.). Authority, therefore, is based on voluntary obedience and, according to Weber (as cited in Bolman \& Deal, 1997) is linked to the respect and legitimacy that people hold toward the authoritative position. This necessary sense of legitimacy must, then, be rooted in at least one of the aforementioned types of authority.

While authority is the right to issue orders, power, according to Fayol (1916), is the ability to obtain obedience from those to whom the orders have been issued. Although one does not necessitate authority to employ the use of power, in order for an organizational leader to exploit the authority which he or she is privy to, they must be able to access a source of power.

Schlechty (2001) explains that the obedience brought about through the use of power is based on the control of essential resources. Mintzberg (1983) further describes the bases of power as control over: resources, technical skill, a body of knowledge, legal prerogatives, and/or access to those who can rely on the first four mentioned. Hoy and Miskel (2005) list several sources of power which coincide and build on Mintzberg's list: (a) reward power is created by rewarding subordinates for desirable behavior, (b) coercive power is founded through punishment for undesirable behavior, (c) legitimate power is tied directly to traditional authority as subordinates respond specifically because of the position of the leader, (d) referent power is related to charismatic authority as 
people follow orders because there has been a bond created with the administrator, and (e) expert power is based on the expert knowledge and skill of the leader. The sources of power defined by Bolman and Deal (1997) mirror those of Hoy and Miskel, and Mintzberg with the addition of: (a) the access and control of agendas, meaning the leader holds a prominent position in the decision making arena; and (b) control of meaning and symbols which define the organization as a whole. The commonalities found in each of these authors lists of the sources of power emphasize the point that there are multiple opportunities for leaders to exercise power from their given positions. Leaders who are able to work efficiently with each source of power, as needed, will find the greatest level of success influencing, motivating, and guiding the members of their organization.

A leader who is adept at using the sources of authority and power available to them will be able to create an environment in which motivation and persuasion of organization members is attainable. Authority and power, if not managed properly, though, do not guarantee motivation among organization members. To assure that all employees are motivated to fulfill their obligations and potential, an administrator must also understand the elements of a work environment that lead to motivation. Herzberg's motivation-hygiene theory lists several factors that lead to job satisfaction, thus motivation: achievement, recognition, the work itself, responsibility, advancement, and growth (NetMBA, 2002). Each of these components provides opportunities to allow job enrichment for employees, which Herzberg maintained, is the key to intrinsic motivation. Bailey (1991) states, as well, that the most important factor in attaining employee motivation is the work itself. Therefore, in order to attain optimal motivation levels for 
employees, the organization's leaders must be certain that the work experience creates individual satisfaction.

Motivating an entire staff and persuading them to concentrate their focus on the goals of the organization is not an effortless task. Leaders must understand the work conditions that allow for such motivation to occur, and be able to employ proper authority and power sources to be able to maximize influence within the occupational arena.

Encouragement and recognition. The final practice of positive transformational leadership to be discussed is encouragement and recognition. Positive recognition and the personal attention of leaders, especially in schools, are in scarce supply (Schlechty, 2001). It follows, therefore, that leaders, who make it a point to emphasize the successful ventures of members of an organization, and their effect on the success of the organization as a whole, can make great strides in increasing the functions of the organization. Fleck (2005) states that successful leaders express their gratitude and send thank you notes when appropriate. Fleck further maintains that leaders should actively seek out positive occurrences, should be active in assisting others to succeed, and should then be sure to personally and publicly recognize those who have attained personal successes and contributed to the promotion of the organization.

The rigidity of the daily work routine, and the pressures associated with a career can cause frustration and disenchantment. Leaders can "encourage the heart of their constituents ... by showing appreciation for individual excellence" (Kouzes and Posner, 2003, p. 6). When accomplishments occur that support the vision of the organization, those involved should be recognized and rewarded (Saphier, 2005). Nelson (1999) states 
that congratulating employees for positive job performance, both publicly and in personal writing, along with celebration of group successes are both instrumental in assuring continuance of positive results. Showing appreciation and celebrating success not only builds a positive and encouraging work environment, but can also alleviate isolation and anonymity within the workplace (Speck, 1999).

Bolman and Deal (1997) also emphasize the importance of celebration and ceremony within the realm of the organization. Ceremonies are employed to recognize and highlight the special moments that occur during the progression of the routine organizational life. Within the symbolic frame of leadership, according to Bolman and Deal, ceremonies not only reward the hard work of selected employees, but also provide opportunities for socialization, stabilization, reassurance, and can convey messages to entities outside of the organization. Recognition of individual and organizational successes can be used to reinforce the progress of the organization; therefore, alleviating many fears and dissatisfactions that may have arisen, both within the organization and with cooperating constituents beyond the internal community of the institution. By incorporating ceremony and recognition into the fabric of the organizational structure, leaders can build a positive work environment that will encourage workers to excel and enable members to maximize work potential.

The intricacies of leadership must be understood by anyone aspiring to pilot an organization through the trials of building and sustaining a successful corporation. While there are certainly numerous aspects of positive leadership that have not been touched upon in this review of literature, the aforementioned aspects are those that have been found as a consensus for maximizing leadership potential. A leader who applies the best 
practices of transformational leadership, which entails the following: (a) shared organizational vision, (b) models desired behaviors, (c) enables others to share in decision-making, (d) motivates individuals to put forth optimal energy, and (e) encourages and recognizes the efforts and successes of all; will be able to build a culture for retaining workers. While much of the established leadership theories are based in the political and business arenas, it is also important to examine leadership study as it applies to education.

\section{School Leadership}

The leadership role specific to this study is that of the local school leader.

Leaders in the field of education often face unique barriers in constructing an environment in which employees are willing to share in the decision making process. As discussed earlier, the norms and values that were established in the era of the one-room school house have led to the perception that teachers conduct themselves as separate entities within the school, and that each classroom is a unique environment within itself. School administrators must recognize, though, that the most successful schools are those that are able to effectively involve teachers in the process of making decisions (Fleck, 2005). Research indicates that teachers demonstrate increased job satisfaction and feelings of professionalism when given roles that allow them real authority (Bailey, 1991). Allowing local educators the occasion for input into curricular and instructional choices creates an environment in which they can thrive, both in the classroom and throughout the school (Bartholomew, 2007). Young's Model of Collegiality (as cited in Bailey) focuses on teachers as colleagues, researchers, and experts. The key is to create 
opportunities where input is truly valued, by the staff and administration, and employed by leaders in the decision making process.

Research indicates that there are a number of alternatives that local school leaders can utilize to increase teacher participation within the school. Barth (as cited in Institute for Education Leadership, 2001) notes that there are ten areas in which teachers should be actively involved in the decision making process:

1. choosing textbooks and instructional materials;

2. shaping the curriculum;

3. setting standards for student behavior;

4. deciding whether students are tracked into special classes;

5. designing staff development and in-service programs;

6. setting promotion and retention policies;

7. deciding school budgets;

8. evaluating teacher performance;

9. $\quad$ selecting new teachers; and

10. selecting new administrators.

Cultivating leadership opportunities school-wide will provide occasions for everyone to employ their talents and will increase the intensity of the commitment of the school faculty and staff (Sergiovanni, 2001). Administrators who are able to create situations in which teachers are allowed meaningful input into the previously listed topics will find that the level of professionalism and commitment of the staff will be enhanced within the school. 
While school principals must involve members of the staff during the decisionmaking process, it is important that they also embrace their role as the instructional leader of the school. Many times it is too easy for school-level administrators to get caught up in the daily grind of managing the school and neglect their duties outside of the office. Fleck (2005) encourages principals to become instructional experts and to "set high expectations for each teacher and student" (p. 101). It is also important to schedule time each week for regular classroom visits (Fleck). Speck (1999) wrote that principals must be willing to deploy themselves by ... "getting out of the office and interacting with others ..." (p. 58). Schlechty (2001) emphasizes the importance for principals to monitor and evaluate the instruction that is occurring within the classrooms of the school, and to enforce the use of proper instructional strategies and adherence to school and district policy. In the report by the National Association of Secondary School Principals (2006) the recommendation that principals be active leaders in curriculum, instruction, and assessment is supported. The only possible way for principals to be effective and respected in this role is to be visible in the classrooms.

One of the primary roles of a local school administrator as the instructional leader is to serve as the evaluator of teachers within the school. If administrators rely on teacher observations and evaluations, though, as the sole source for information on the classroom, they will find that there is not enough time in the school day to get an accurate account of classroom activities. The state of West Virginia, along with many other states, has started the initiative of classroom walkthroughs. High Schools That Work (n.d.) includes the classroom walkthrough as a valuable instrument for administrators to employ to support changes in the structure of teaching and learning within the school. 
Classroom walkthroughs are brief in nature, yet provide an excellent opportunity for administrators to observe daily occurrences within teachers' classes. Wexford-Missaukee ISD Effective School Toolkit (n.d.) provides a guide for administrators to gauge student involvement, the past and present objectives being taught, instructional strategies in use, and the presence of any safety concerns. The classroom walkthrough is an effective, nonevaluative tool that can be used to observe many classrooms within a single time period during the school day.

Administrators can also gain a feel for the occurrences within a school by conducting informal conversations with faculty and students. "Frequent informal conversations help the principal to keep a pulse on [school-related] concerns and assist [dealing with] them when necessary" (Fleck, 2005, p. 49). It is important for administrators to take the time to engage with others within the school in order to be aware of, and demonstrate concern for the issues that arise over the course of the day.

By allowing teachers the opportunity to play a meaningful role in school-wide decisions, and embracing the role of the instructional leader, a school principal can assure that all members of the school are working toward the common goals and vision of the school. The local school is a unique situation within the realm of professional workplaces, and there are many obstacles that a principal must overcome in order to secure school-wide participation toward attaining the goals of the school. The research and considerations for operation outlined in the previous section denote the best practices for the creation and maintenance of a retentive school culture in which the staff and faculty are willing to work in conjunction with the school's administration. 


\section{School Culture}

The culture of an organization is not always readily apparent, but is certainly a major influence on the success the organization. While, "culture is elusive ... we ignore it to our detriment" (P. Noguera, personal communication, August 6, 2008). Rules, policies and procedures, mission statements and objectives are put into writing and should be evident upon acculturation into an organization; often, though, a great deal of diligence is needed to truly understand the organizational culture that has been established within an institution.

To uncover the culture of an establishment, one must first understand what the term organizational culture means. According to Hoy and Miskel (2005), organizational culture is a system of shared orientations that hold an institution together and give it a distinctive identity. More simply stated, it is "the way we do things around here" (Deal \& Kennedy, 1982, p.4). Schein (1993) points out that the culture of an organization is built as the conglomerate processes through internal and external conflict and adapts to areas of stress. The assumptions that are constructed during this progression, and which have proven to be valid, are then passed on to new members of the group "as the correct way to perceive, think, and feel in relation to those problems (p. 365). P. Noguero (personal communication, August 6,2008) defines culture as the beliefs attitudes, norms, and expectations that guide individual actions within an organization, and the overall actions of the organization as a whole. Cultural aspects of an organization, therefore, should bind the individual members of the group into a cohesive entity, much like a family unit, that approaches given scenarios from a common point of view and with an established set of procedures. 
The specifics of an organization's culture may vary between institutions, but there are common elements that underlie the creation of organizational culture. Hoy and Miskel (2005) describe three symbol systems that are incorporated into an organization's culture: (a) stories, which are based on true events yet entail a portion of fiction; (b) myths, which communicate unquestioned belief and are not upheld by any facts; and (c) legends, which are simply stories that have been retold on numerous occasions and have been supplemented with additional fictional details. Bolman and Deal (1997) caution that, while myths can be used to create solidarity and cohesion within the group, they can also distract curiosities and attention that may otherwise serve to promote the overall cause of the organization. Bolman and Deal also emphasize the fact that stories are not entirely separate from myths. Stories are used to establish tradition, but also are the primary means for communicating myths. These stories inculcate traditions of the establishment, both to those inside the organization and to outsiders, as well. According to Hoy and Miskel, in addition to these three systems of symbols, many organizations have icons and rituals that also contribute to the culture. Icons (i.e. logos, mottos, and trophies) are physical artifacts that express the established culture. Rituals are routine ceremonies and rites that communicate what is important to the individuals within the organization, as well as, the organization as an entirety. Martin (2002) states that rituals are those repeated actions of the organization that are carefully planned, executed, and carried out in a social context. Cultures rely heavily on rituals to "to create order, clarity, and predictability" within the everyday occurrences of organizational life (Bolman \& Deal, p. 223). Martin also accentuates the importance of technical and emotional jargon, 
humor, the physical arrangement of the building and individuals, and formal and informal practices in creating the organizational culture.

Schein (1993) defines several more aspects that formulate the culture of an organization:

1. observed behavioral regularities when people interact;

2. group norms, meaning the implicit standards and values;

3. espoused values that articulate the principles which the group is working toward;

4. formal philosophy, which is the ideological principles and policies that guide the group's actions;

5. rules that all members, including newcomers, must learn;

6. climate, specifically the feelings conveyed as people interact;

7. embedded skills that are not in writing, but passed along within the group;

8. habits of thinking, mental models, and/or linguistic paradigms;

9. shared meanings among the individuals in the group; and

10. root metaphors or integrating symbols which show how the group characterizes itself.

Each of these aspects contributes to the patterns and mannerisms of the organization that allow it to adapt to external and internal pressures, establishing the routine flow of daily interactions and processes.

An organization's culture may cultivate itself through the interactions of the members that constitute it, but it would be unwise for an organizational leader to 
allow such development to occur unattended. Therefore, there is a fundamental relationship between the leadership of an organization and its cultural characteristics. According to Schein (1993), “... one of the most decisive functions of leadership is the creation, the management, and sometimes even the destruction of culture" (p. 361). Since the establishment and maintenance of culture often includes conflict and ambiguity (Martin, 2002), leaders should remain vigilant to assure that negativity does not manifest itself within the cultural aura. P. Noguera (personal communication, August 6, 2008) notes that the distinguishing factor between highly effective organizations and others is the culture that they create. Cottrell (2008) affirms that positive energy among an institution's leadership staff will promote passion and satisfaction, which will, in turn, lead to positive cultural understandings among group members. Indeed, organizational leaders should strive to establish a positive culture that promotes the qualities and characteristics that will allow the organization to thrive.

Within the realm of public schooling, culture is created at the local level (Bartholomew, 2007). This fact allows the local administration and school leadership to play an active role in the establishment of a school culture that will encourage staff and faculty, and maximize the benefits for students. Sergiovanni (2001) maintains that successful principals are those that remain diligent to the creation of opportunities that allow them to affect the elements within their schools; one of which is the cultural wellbeing. This requires vast awareness of the "informal, subtle, and symbolic aspects of school life" (p. 112). The creation of a personalized school climate is beneficial to both students and teachers (David, 2008). By maintaining an influential presence within the school and establishing those characteristics that lead to positive cultural elements, school 
administrators can provide a positive work environment for faculty and staff members, and; therefore, promote the academic well-being of the students that are serviced within the school walls.

It is apparent that the construction of a positive organizational culture can be a taxing and time consuming task for leaders. It is necessary, none the less, to assure that cultural elements are put into place to build an environment that is conducive to maintaining long-term commitment from the individual members that constitute the organization. Every organization contains a culture, and one will find many of the previously mentioned cultural elements within any institution upon investigation. It should be the priority of those committed to the organization to assure that this culture promotes the achievement of the mission and goals upon which the organization is founded.

In order to create a culture within the local school that is conducive to teacher retention, the building level administrator must understand both the criteria that lead to teacher motivation and those that inhibit cooperation within the teacher ranks. While all of these conditions are not necessarily created or influenced by building level administrators, an understanding of these circumstances can certainly prove beneficial in the quest to create a retentive culture among a school's faculty and staff.

\section{Teacher Motivation}

There are many aspects of the daily life within a school building that influence the cooperation, or lack thereof, of the teachers. Administrators can certainly demonstrate the leadership skills necessary to create a successful school, and set in motion those processes that influence a positive culture, but without the support of the teachers, the 
construction of a retentive school culture will not occur. There are advantages for those administrators who understand the mindset of the teachers within his or her building. In order to do so, it is necessary to examine the conditions to which teachers are exposed in public education and the resulting trends that are occurring in teacher attrition.

Conditions of teaching. The federal government has established itself as a major influence on the mission and objectives of the local school. With the institution of the No Child Left Behind Act (NCLB) (United States Department of Education [U.S. DOE], 2002), the federal government has increased the level of expectations for student demonstration of content mastery within the core subject areas of mathematics, reading and language arts, science, and social studies. As state and local boards of education strive to choreograph policies and procedures for staff development, student testing, and administrative practices that will lead to district wide attainment of these standards, the pressure falls on classroom teachers to assure that their students are capable of passing the state-wide standardized tests that serve as the sole measure of content mastery. The NCLB Act has led to wide-scale reformation movements that many teachers find intrusive and unsubstantiated.

Because of the pressure to ensure student preparation for standardized tests, many teachers feel threatened and stifled in the content that they are able to teach ("Spellings Hears Tales," 2008). Many teachers avoid exploratory, project-based, and standardsbased instructional designs because of the amount of time necessary to coordinate the activities with their students (Kennedy, 2005). Most instructors feel pressure to cover the state designed curriculum, and find that they are rushing through topics in order to ensure that students are exposed to all required course content. Because of the fear that students 
will not perform well on the high-stakes standardized tests, many teachers are reluctant to experiment with instructional and evaluation techniques. There is an encompassing belief that there are limited opportunities for trial and error, and reflection. The resulting restriction of academic freedom "combined with the looming spectacle of working in a school labeled as failing, deals a blow to teacher morale" ("Spellings Hears Tales," 2008, p. B5). P. Noguera (personal communication, August 6, 2008) notes that labeling a school or teacher as failing does little to improve performance. Many teachers will shun exploratory techniques and instructional strategies, to avoid this label to start with, creating maintenance of status quo teaching performance.

The NCLB Act is not the only performance-based cause of stress for public school teachers. Modern education finds itself in a continual cycle of reform. Kennedy (2005) notes that modern reform ideals include: more rigorous and important content, more intellectual engagement, and a universal access to knowledge. While these principles seem to be unpresumptuous in nature, Kennedy's research concludes that teachers lack sufficient knowledge and guidance to enact substantial instructional changes, teachers still hold beliefs and values that differ from those of most reformers, teacher dispositions interfere with proper implementation of reforms, circumstances within the course of the school day prohibit drastic classroom changes, and that many reform ideals are not realistic. Compounding the stress that reform causes teachers is the fact that there is no time built into the school day for teachers to continue study in their field or to further their knowledge of instructional techniques (Wineburg \& Grossman, 1998). While educators certainly hold the value of each child's education at a premium, and fully intend to maximize the educational experience of every child, the details of 
classroom life often constrain their ability to teach. The fact that many educational outsiders are not familiar with the conditions inside the classroom and do not understand the dispositions of many modern educators leaves numerous teachers feeling misunderstood and unappreciated.

Among public school faculty, the sentiment remains that teachers are left out of any initial stages of the change process. Hennessy, Ruthven, and Brindley (2005) note that teachers often do not have input into the implementation or design stages of reform, and programs rarely take into consideration the teachers' perspectives. The political nature of educational reform and accountability leaves many teachers feeling helpless and vulnerable. The top-down design of the decision-making process in education seems to be driven by the input of the external community, while disregarding the thoughts of teachers (McGrail, 2006). These trends have not fostered a healthy approach to cooperative and sustaining change among the ranks of the teachers, and have not led to an overall educational culture that lends itself to true transformation at the base level; the classroom.

Instead of cooperating with administrators and reformers in education, many teachers prefer the isolation and autonomy that has been created within classrooms throughout the history of public education. Unfortunately, it seems that the mindset of many teachers demonstrates a tendency toward a closed-door classroom. These teachers perceive their job as handling the occurrences within their classes and make little effort to collaborate, interact, or function with other professionals in the school. While there are certainly a number of teachers that understand the importance of viewing the school as a whole, "... history, culture, and school building construction encourage teacher isolation 
..." (Bailey, 1991, p. 114-115). Over time, the tendency to focus solely on one's own class can negatively affect a teacher's loyalty to the school and perception of self-worth.

Locally, the benefits and salaries that teachers receive have proven to be an obstacle in the creation of a retentive culture in schools. West Virginia continues to rank at the very bottom of the national stage when comparing teacher salaries. The eastern panhandle of West Virginia is in close proximity to several counties in Virginia and Maryland that offer more lucrative pay packages for teachers; influencing a large amount of teachers, on a yearly basis, to commute to schools outside of the state. Many teachers deem the lack of financial support as a deficiency in the concern of state leaders,

Instructional leadership has begun to attempt to change the reclusive mentality that currently abounds among educators. Bailey (1991) contends that teachers are now being asked to work cooperatively with other teachers and administrators to create a school-wide instructional program that will benefit all students within the school. Studies demonstrate that "... good teaching thrives in a supportive learning environment created by teachers and school leaders working together to improve learning ..." (National Commission on Teaching and America's Future, 2002, p. 11). It is apparent that a great deal of work is required to redesign the scope and sequence of educational reform, the political nature of program implementation, the isolation of teachers in the classroom. and the low salary scale of teachers; which are all contributing factors that impede the process of reform and the creation of a retentive culture. The process toward these changes has begun and has shown solid signs of success. Still, the exodus of teachers from their current positions causes a great deal of concern, and should be examined. 
Trends in teacher attrition. Numerous studies reflect the fact that many individuals who enter the education field do not spend their entire professional lives as teachers. "Every school day, nearly a thousand teachers leave the field of teaching, ... [and] another thousand teachers change schools" (Alliance for Excellent Education, 2005, p. 1). Not only do teachers tend to move out of the classroom, but many spend a relatively short amount of time in the profession. The United States Department of Education (2010) found that over 527,000 teachers transferred schools or left the profession of education following the 2008 school year. Weld (1998) cites statistics revealing that only $56 \%$ of 13,000 teachers studied in the state of Michigan in the 1970 's were still teaching after six years. Haberman and Richards (1990) found that approximately one-half of teachers nation-wide resign within the first six years. Budig (2006) provides research that shows $50 \%$ of teachers today last only five years. According to Fulton et al. (2005), one-third of American teachers leave during the first three years of their experience. Furthermore, a 1993 RAND Corporation study (as cited in Weld, 1998), found that the average lifespan of chemistry teachers, one of the highneed areas defined by the West Virginia Department of Education (2007), is four years.

Causes for teacher attrition are well researched within the education profession. Weld (1998) discovered that very few teachers who leave the classroom do so because of monetary reasons. Still, studies have shown that teaching is one of the nation's poorest paid professions at the entry level (Budig, 2006), and certainly, most aspiring educators are aware of the low pay scale when beginning their preparation. Studies conducted as long ago as 1843 revealed that every professional trade received higher wages than the public school teacher (Katz, 2001). So, while the salary scale of public educators may 
not be the primary reason that many leave the teaching profession, monetary compensation is most definitely not viewed as an incentive for remaining in the educational field.

Locally, in Berkeley and Jefferson Counties of the eastern panhandle, the turnover of teachers and increase in student population has caused a rising sense of concern among the public and local school officials. These two counties have had the largest increases in student population in the state. While the overall student population in West Virginia has decreased from 2008 to 2009 , the number of students in Berkeley and Jefferson counties continues to increase. Since 2004, West Virginia's Educational Personnel Data Report (2009) shows that Berkeley County's student population has increased by 2,231 . The student population is projected to continue increasing at a substantial rate in Berkeley County through 2011. The trend is similar in Jefferson County, as the student population has risen by 726 students since 2004 , and is also projected to increase through 2011 . The statistics indicate that this increased enrollment, along with teacher attrition, has caused a shortage of qualified teachers in these two counties. As compared to the state average of $15.7 \%$ of teachers who have three or less years of experience, Berkeley County has $22.2 \%$ and Jefferson County has $24.1 \%$ of classroom educators who have yet to reach four years of classroom experience. Since 2004, Berkeley County has had to hire 485 long-term substitutes to fill vacancies for which there were no qualified applicants, while Jefferson County has had to hire 214 long-term substitutes. In the 2006-2007 school year, a Berkeley County report showed that 113 teachers left the Berkeley County School system. Forty-five percent of these teachers resigned to take teaching positions in another state (J. Schooley, personal communication, September 18, 2008). Beginning the 
2007-2008 school year in Berkeley County, there had been 367 professional postings. Forty percent of the teachers leaving left for another state, and eight percent took jobs outside of the education profession. Of these postings, over 20 percent were not filled with a qualified applicant (J. Schooley). The significance is clear, as schools in the eastern panhandle are compelled to hire less qualified, or even unqualified, personnel to fill the vacancies left by teacher turnover and attrition, and the new positions needed due to an increase in student enrollment, the struggle to provide a high quality education for all students will continue to be a difficult issue for school and county level administrators.

To discover the reasoning behind the high attrition rate of teachers, it is necessary to look beyond the obvious concerns of salary and benefits. Weld (1998) cites four criteria that must be addressed in order to retain high quality teachers. According to Weld, leadership must be concerned with (a) the sense of isolation experienced by teachers, (b) the lack of reception for innovative ideas by administrators, (c) classless compensation schemes for teachers, and (d) a lack of recognition of the professional aspect of teaching. Stevenson, Dantley, and Holcomb (1999) display statistics showing that fifty percent of teachers who abandon the teaching profession cite lack of administrative support and a lack of recognition as primary reasons for leaving the classroom.

Berry (2005) writes that along with poor support from administrators and a lack of influence over the creation of policies, teachers often leave because of poor student motivation and discipline. Along the same lines, Stevenson et al. (1999) conclude that 
assistance with student discipline would provide incentive for many teachers to remain in the field.

Studies have shown that seven thousand students drop out of school on an average school day, and six million others are at risk for not graduating with their class, or graduating without the skills necessary to be successful in a twenty-first century society (Alliance for Excellent Education, 2005). It is apparent that these students, in particular, need the best teachers available to increase their skills and mentor them through the educational process. Whatever the cause behind the enormous deficit in highly qualified teachers facing modern schools, there is no doubt that a resolution is desperately needed. Facts concerning organizational culture and leadership characteristics must be closely examined to provide an in-depth, knowledgeable approach to constructing a school environment that is conducive to reversing the current trends in teacher attrition and turnover.

Among the strategies that have been employed by administrators to address the issues that lead to teacher attrition is the creation of professional teacher networks. This tactic has demonstrated tremendous success in the areas of teacher growth, education, and retention.

\section{Professional Teacher Networks}

One of the most effective methods for creating prospects for teacher leadership and input is the creation of professional learning communities. Teacher professional learning communities, or networks, are defined "... as groups of teachers organized for purposes related to teacher learning, inquiry, support, or school improvement" (Niese, 2007, p. 605). One of the key benefits of these networks of teachers, which can be as 
simple as department teams or can involve teachers from several departments, schools, or even districts, is the expansion of leadership opportunities for educators (Pennell \& Firestone, 1998). Inside of these networks, teachers are viewed as the experts, and opportunities are provided to interact with one another, honing their craft and increasing their instructional abilities. Professional learning communities allow teachers to feel as if they are respected as professionals, positively impacting their identities within the school (Niese). It is the administrator's job to free up time for teachers to interact within these networks. Creating common planning periods, providing substitute teachers for meetings during the school day, and stipends for after school meetings and summer retreats are all methods that have been successfully employed to allow the necessary time for such engagements (Wineburg \& Grossman, 1998).

Fitzpatrick (2001) describes an elementary school setting that has instituted teacher networks as a means for allowing teacher input in school improvement initiatives. Teachers meet in small grade level groups in sessions that are facilitated by a member of the school's Site Committee, which are also teachers. All members of the Site Committee meet as well to merge concerns and ideas from the teacher groups, and to determine items that need to be passed on to the principal or disseminated throughout the entire faculty. Information is passed between the principal, Site Committee, and teacher groups as needed. Through this process teacher input is considered and employed in all decisions regarding implementation of improvement plans. The principal in this school noted that there has been improved implementation of decisions based on the increased empowerment of the staff, shared leadership, and greater sense of ownership among the faculty and staff. Individual teacher interviews indicated that the faculty felt an increased 
level of professionalism, ownership, and commitment due to this arrangement. It was their perception that the administration placed a high value on the opinions of the staff members.

The model of teacher networks defined by Wineburg and Grossman (1998) is used primarily for staff development, but they also found that these learning communities create an environment of shared interests and support among the faculty. Aspects of their model have been used to overcome "... the culture of privatism that pervades schools" ( $\mathrm{p}$. 352). Pennel and Firestone (1998) echo the results found by Fitzpatrick (2001) that teachers involved in networks experienced an increased sense of professionalism, and found that their needs are better addressed when operating in this model of staff development, and shared leadership and decision making.

The connections to the school and fellow teachers that are created through the networking process increase the commitment that teachers feel toward their work and school (Niese, 2007). Networks also increase the level of trust that teachers have for their colleagues and administrators (Penuel \& Riel, 2007). The creation of these connections and faculty trust are core components to retaining the qualified teachers that currently exist in the public school system. While professional teacher networks are a primary method used in creating and maintaining a school culture conducive to teacher retention, recent research in the creation of retentive cultures has identified several other effective strategies, as well.

\section{Recent Research in the Creation of a Retentive Culture}

As the nation-wide problem of teacher attrition has continued to effect public education, there have been numerous studies designed to seek out the reasons that 
teachers leave the profession, and to help administrators create a culture that is conducive to teacher retention. While the results of each study vary, researchers consistently find that the school leadership and cultural conditions within the school play an important role in the determination of teachers to stay or leave.

The factor found most consistently to be instrumental in teacher decisions to leave or stay is the quality of the school leadership. McKee (2003) determined that school leaders can unknowingly affect the teacher attrition rate as the administration was ranked very highly as a determining factor for those teachers who left, while administration ranked low among those teachers who have remained in the field as a reason for staying. Conversely, in a study of urban teachers, Blanson (2005) cited administrative support as a key factor for those teachers who have stayed in their current schools. Principals surveyed by the Charlotte Advocates for Education (2004) felt that strong school leadership and teacher support were very instrumental in creating a culture of retention among their staffs. It is evident from current research that the school administration is influential in both teacher attrition and retention. Caring, open, and professional administrators are much more likely to be able to retain their teachers than are those leaders who do not display such characteristics (Blanson, 2005).

The culture of the school is another primary reason that teachers cite for either leaving or staying in the education profession. Working conditions within a school make a significant difference in relation to teacher attrition (Charlotte Advocates for Education, 2004). Blanson (2005) cites the creation of classroom and school environments in which teachers feel they can make a difference in the lives of students and influence the community as a primary cause for teachers to remain at their school. Teachers who have 
been loyal to the education profession, to a great extent, have been so because of emotional reasons (McKee, 2003), which can be influenced by the culture of the school.

Blanson (2005) initiated a case study, with a qualitative design, of the Aldine School District in Texas in order to research the reasons that teachers choose to stay in their current positions within an urban school setting. Blanson selected a school within the district that had a low turnover rate, and used in depth interviews with teachers for data collection. Only teachers who had five or more years of experience were selected for this case study. After finding that 31 teachers within the selected school met this qualification, Blanton narrowed the sample so that it was ethnically diverse, included teachers that had a wide range of teaching experience, was gender balanced, and had teachers who had spent the last five years within the selected school.

Blanson (2005) used a semi-structured interview to illicit the data from the participants. An informal setting was created, and open-ended questions were used to encourage participants to detail their experiences and reasons for staying in their jobs. These interviews were taped, with the permission of the teachers.

Blanson (2005) analyzed the collected data using narrative analysis methods. Blanson identified similarities, commonalities, and patterns in the teachers' stories. Blanson employed grounded theory identifying categories and concepts that could be linked to substantive and formal theories. Analysis of verbatim transcripts and memoing were used to identify potential themes and to document links between these themes.

Blanson (2005) found that strong administrative support, the belief that teachers can make a difference in the lives of their students, and the fact that there was no necessity to leave were strong influences on teachers to stay in their current positions. 
Leaders who are caring, open, and professional were found to have a greater probability of retaining their staffs than those leaders who do not display these characteristics. Blanson also collected data that led to the assertion that mentoring does not play a large role in a teacher's decision to remain in the classroom, and that professional development plays a menial roll in this decision.

Recent research in the area of creating a retentive culture in schools has consistently noted the importance of school leadership and culture as determining factors for staying in, or leaving, the classroom. These studies have led to the creation of the research questions that will be addressed in this case study:

RQ1. What are the leadership practices of a principal in a selected high school that has a high teacher retention rate in a region of West Virginia?

RQ2. Why do teachers stay in a selected high school that has a high teacher retention rate in a region of West Virginia?

RQ3. What contributes to a school culture that retains teachers in a selected high school that has a high teacher retention rate in a region of West Virginia?

As the recognition of the importance of school leadership and school culture for the creation of a retentive culture have come to the forefront, it is imperative to find out the leadership practices that a building level administrator should employ, and the cultural conditions that schools with a retentive culture display. 


\section{Chapter Three: Research Method}

The purpose of this study is to identify the emerging themes that may be affected by school building principals who foster a culture that enhances teacher retention rates. Chapter Three provides the framework that will be employed in order to carry out the research. Among the topics discussed in this chapter are: (a) qualitative research design, (b) the retentive school culture from a qualitative perspective, (c) the researcher's perspective, (d) the selection criteria for the school to be studied, (e) the characteristics of the research site and participants involved in the study, (f) the Leadership Profile Inventory (LPI) instrument and procedures for data collection, $(\mathrm{g})$ ethical considerations, and (h) the data analysis methods. The results of this study provide a framework by which a building level administrator can influence the necessary components of a positive school culture; thereby, promoting teacher retention.

\section{Qualitative Research Design}

This research was a case study of one selected West Virginia high school designed to answer the following research questions:

RQ1. What are the leadership practices of a principal in a selected high school that has a high teacher retention rate in a region of West Virginia?

RQ2. Why do teachers stay in a selected high school that has a high teacher retention rate in a region of West Virginia?

RQ3. What contributes to a school culture that retains teachers in a selected high school that has a high teacher retention rate in a region of West Virginia? This case study uncovered the leadership and cultural elements within a school from the viewpoints of the administrators and teachers involved in the school setting. 
This research, therefore, is predisposed to the use of qualitative methods as a means "to understand some social phenomena from the perspectives of those involved [and] to contextualize issues in their particular socio-cultural-political milieu ..." (Glesne, 2003, p. 4). In this study, the researcher strove to illicit the practices of administrators, teachers, and parents within the school setting and to determine "... how people make sense of their experience..." (Merriam, 2002, p. 5). An instrumental case was chosen in order to shed light on and understand a given phenomena (Stake, 1995). This research was an instrumental case study as the researcher focused on teacher retention as the school represents the issue (Cresell, 1988). Qualitative research is especially useful in this instance, as the data allowed the reader the opportunity to understand what it is like to be within the school, as the data captured and illuminated the experiences of those within the setting (Patton, 2002).

Qualitative data “... are a source of well-grounded, rich descriptions and explanations of processes in local contexts" (Miles and Huberman, 1994, p. 1). This study provided descriptions that lend insight into the consequences of actions taken within the school setting, and help make sense of these outcomes (Miles and Huberman). Gay, Mills, and Airasian (2006) express the belief that qualitative data are preferential to quantitative as findings "... should be derived from research conducted in real-world settings in order to have relevance in real-world settings" (p. 400). By immersing the data collection within the school environment, the research provided an in-depth experience pertinent to modern educators, and maximized the opportunity to discover the "... meanings people place on the events, processes, and structures ..." that occur on a 
regular basis within the school setting that are relevant to teacher retention (Miles and Huberman, p. 10).

\section{Retentive Cultures from a Qualitative Perspective}

In the study of teacher retention, qualitative research methods have been found to be an effective means for data collection and analysis. Miles and Huberman (1994) describe local groundedness, and richness and holism as two primary strengths of qualitative research. When studying school cultures, in relation to teacher retention, local groundedness is important as the researcher should analyze data that has been collected specific to the site to be studied. The data collected from those within the school setting provided a realistic, truthful account that lends to the richness and holism of the study. Previous qualitative studies in the area of retentive school cultures provided a guideline for best answering the research questions of this study.

Perrachione, Rosser, and Peterson (2008) conducted a mixed methods study seeking to provide insight into the relationship between teachers' job satisfaction and teacher retention. Perrachione et al. acknowledge that, while there is a significant amount of research focusing on teacher attrition, there is a lack of research examining why teachers stay in their schools. This study used a quantitative instrument which included a shortened version of the Schools and Staffing Survey (SASS), developed by the U.S. Department of Education, as well as additional quantitative sections that were developed specifically for this research. The researchers supplemented their study with a qualitative component which consisted of six open-ended questions designed to provide further insight into the teachers' perceptions concerning their job satisfaction. 
Perrachione et al. (2008) used descriptive statistics and linear regression analysis to study the quantitative aspects of the study. These statistical methods were used to present the concepts that were perceived as contributing factors for teacher retention. Inductive analysis was used to examine the open-ended questions. Common viewpoints and perceptions were used to define coding categories. Responses were placed in these categories, which allowed analysis of teachers' perceptions on job satisfaction and their intent to stay in their current jobs. The researchers recommended that further study be conducted to differentiate between teachers' satisfaction with the education profession and their satisfaction with the job of teaching. They also promoted the need to further distinguish between teachers' commitment to the teaching profession and their commitment to the school in which they are currently employed.

Clayton and Schoonmaker (2007) conducted a qualitative study to analyze teachers' commitment to the profession of education. This inquiry studied three teachers who were chosen based on their graduation from a common pre-service program and similar academic backgrounds. The authors analyzed data collected through documents including: student-teaching journals and papers, observation reports and literature, records of classroom observations, existing interviews with the three teachers and preservice faculty members, and in the case of one teacher, interviews with a principal and former students. Furthermore, unstructured interview protocols were developed for the teachers. Transcripts of these interviews were analyzed by the researchers.

In analyzing the data, Clayton and Schoonmaker (2007) developed narrative portraits of the three teachers, and used grounded theory to construct insights across the collected data. Constant comparative method was used to code data in a way that 
allowed " ... both narrative and explanatory representations of [the researchers"] interpretations" (p. 251). The researchers suggested that further inquiry into the area of teacher retention and development is warranted, as well as additional study into the socialization of teachers in regards to their development, and efforts to better prepare teachers through university and school cooperation.

Buchanan, Bleicher, Behshid, Evans, and Ngarupe (2007) conducted a qualitative study to research teacher retention at two Professional Development Schools (PDS). This study examined how teacher needs and expectations were met within the research sites. The researchers employed an interpretive design in order to analyze "... actions from the participants' point of view" (p. 5). Teachers were interviewed, and this data was triangulated with field notes and discussions among the researchers concerning the findings and possible interpretations of the data.

Buchanan et al. (2007) used grounded theory to determine meanings of the data and develop explanatory models. Emergent themes, regarding the definition of professional development and teacher successes, were determined using the interview data. The researchers allowed for continuous data collection and prolonged engagement in the field, and used critical team discussions in order to ensure the quality and trustworthiness of the study.

The mixed methods study of Perrachione et al. (2008) supported the fact that both internal and external factors can have a positive influence on teachers' job satisfaction and their intent to remain in the teaching field. Clayton and Schoonmaker (2007) concluded that the school environment plays a critical role in supporting teachers within the school. Buchanan et al. (2007) found that teachers working in the Professional 
Development School felt that there content knowledge had deepened, communication had been established across the staff, and that there was continuity in the educational process within the school. While each of these studies showed that culture plays a role in establishing teacher satisfaction and dedication, the researchers commented that further qualitative study was needed to better understand the influence that culture and leadership have on teacher retention.

The examples of these studies indicated the usefulness of qualitative methods in the research of teacher retention. The completion of this study within the local schools allowed for the groundedness of this research. The examination of school documents and personal interviews, combined with the LPI instrument in this study, contributed to the richness and holism that qualitative methods promote. Based upon the example of past qualitative research in the area of teacher retention, the researcher employed these methods to extrapolate the unique perspectives of the participants within the confines of a local school that has shown a high rate of teacher retention.

\section{Researcher's Perspective}

Due to the nature of qualitative study, the researcher played an essential role in the gathering, assimilation, description, and analysis of the data. Miles and Huberman (1994) maintain that the researcher is the primary measurement device used in qualitative study. As the researcher becomes immersed within the environment to be studied, it is the insight of the researcher that sheds light on the collected data. The evidence uncovered within a qualitative study is magnified through the perspective of the researcher, as he or she describes the data; allowing the reader a description of the details and events that occur within the natural setting of the study. 
Merriam (2002) acknowledges that "the human instrument has shortcomings and biases that might have an impact on the study ..." (p. 5). Therefore, it is important for researchers to identify their own perspectives and to recognize the biases that may be existent prior to and during the research in order to "... disclose to their readers where self and subject become joined" (Peshkin, 1988, p. 17).

The researcher in this study was an assistant principal at a high school in Berkeley County West Virginia. Berkeley County is currently the fastest growing school system in West Virginia, and is presently maintaining a steady increase in student population. Berkeley County, in the eastern panhandle of the state, is within close proximity to schools systems in Maryland, Virginia, and Pennsylvania that offer a substantially larger pay package to educators; causing many West Virginia teachers to seek employment outside of the state.

During the administrative tenure of the researcher, which spans nine years, the school has replaced 101 teachers; many of whom have left for jobs at other schools. According to West Virginia's Educational Personnel Data Report (2006), Berkeley County has the second highest percentage of teachers with three or less years of experience. Another eastern panhandle school system, Jefferson County, has the highest percentage of new teachers. This same personnel report illuminates the fact that Berkeley County leads the state in the number of substitute teachers that are required to fill full time teaching positions, as there are not enough highly qualified applicants to fill the postings that are necessitated by teacher resignations and additional positions that are created due to the increase in student population. 
As educational standards and expectations continue to increase due to national and state level reforms, the researcher understands the value in maintaining a highly qualified staff of teachers. The efforts necessary to hire and train new teachers is taxing on both the faculty and administrative staff. Several studies, previously cited, have shown the significant importance that experience plays within the classroom; therefore, the researcher desired to understand the best methods for assuring teacher retention.

The interest of the researcher affected an educational bias toward the study of school cultures which are conducive to high teacher retention rates. The bias of this researcher was the belief that leaders do have an impact on the culture of a school. The method chosen for this study, though, rendered answers to important questions which extended beyond this bias. In fact, it was the experience and skill set of the researcher which led to the formation of the research questions. This study provided the opportunity to employ the educational bias of the researcher to attain the unique perspective that subjectivity allows (Peshkin, 1988).

\section{Selection Criteria for School}

The proposed research was a case study of a selected West Virginia high school in the eastern panhandle of the state. The school selected met each of the following criteria:

1. the high school with the highest teacher retention rate among other high schools in the county,

2. a teacher retention rate among the top five of all schools in the county,

3. a principal who had maintained this position over the past three academic years,

4. the researcher was not a member of the community, and 
5. the school was in an area in close proximity to states that have better pay packages for teachers.

The school examined in this case study was selected using the concept of an extreme case. Such selection was based on the determination of a particularly successful example of the case to be studied (Flick, 1998). This instrumental research study focused on the characteristics of a school and a school's leadership, as reflected in the selected school, which positively affected the teacher retention rate. The selection of this site provided emerging themes relevant to this school that led to high teacher retention, but may not necessarily be used to understand other cases (Stake, 1995). The research was conducted from the perspective of interpretive inquiry, as the evidence of the everyday social life within the school walls was examined in a method that sought to ensure an objective study of the school (Soltis, 1984).

\section{Characteristics of the Research Site and Participants}

The school selected for this research was identified by the county Personnel Office as the high school within the district that has maintained the highest rate of teacher retention over the past three years (see Table 1). This school also had the same principal over this three year time span. 
Table 1

Selection Criteria for School Participation in Leadership for Teacher Retention

\begin{tabular}{llll}
\hline School & RR & CR & PT
\end{tabular}

High School A

.922

4

11

KEY $\quad \mathrm{RR}=$ Teacher Retention Rate $\quad \mathrm{CR}=$ County Ranking for Teacher Retention Rate $\mathrm{PT}=$ Principal Tenure 
The participants included in the LPI for this study consisted of five administrators, both county and site-specific building level, and $67 \%$ of the teacher from within the school.

Qualitative research "... is used to understand some social phenomenon from the perspectives of those involved ..." (Glesne, 2003, p. 4). Therefore, the scope of participants was selected on the basis of being able to provide an in-depth understanding of the leadership practices and cultural aspects of the school which lead to teacher retention.

The criteria for the selection of the participants were as follows:

1. County administrator with the most contact with each school; $\mathrm{n}=1$,

2. All school administrators at the site selected; $\mathrm{n}=5$,

3. All teachers within the school selected were asked to complete the $\mathrm{LPI} ; \mathrm{n}=111$,

4. Teachers were randomly selected for the interview; $n=16$.

While the county administrator and all building-level administrators completed the LPI and participated in the interview process, only 16 teachers were selected for the interviews. These teachers were randomly selected. The mean years of experience for faculty members participating in the interviews was 15.25 years, with a range of seven to 36 years. The mean number of years that the participating faculty members have been at this selected school was 12.5 years, with a range of one to 36 years. The faculty members chosen to participate in the interviews included four mathematics teachers, four English teachers, two physical education teachers, two social studies teachers, two science teachers, one special education teacher, and one guidance counselor. All teachers in the selected school were asked to complete the LPI. 
The identification of the research participants helped the researcher ascertain the emerging themes regarding how this school maintains a high rate of teacher retention. The participants provided the descriptive data necessary for this qualitative research study.

\section{LPI Instrument and Procedures for Data Collection}

The LPI is a 360-degree assessment instrument that allowed the school principal to take a self evaluation, while others with whom the principal worked completed the LPI-Observer questionnaire (Kouzes \& Posner, 2009). Participants ranked the principal on a scale of one to ten on 30 leadership behaviors, while the principal ranked himself using the same criteria. These behaviors fall into The Five Practices of Exemplary Leaders, as defined by Kouzes and Posner (2003):

1. Model the way

2. Inspire a shared vision

3. Challenge the process

4. Enable others to act

5. Encourage the heart.

An LPI report was then generated which provided numerical and graphical representations of the data, a mean score from the data collected from the observer questionnaires, a percentile ranking of the leader within each of the five practices, and the results of open-ended essay questions.

Both internal and external studies have verified the face validity of the LPI (Kouzes and Posner, 2002). The predictive validity has also been demonstrated to be strong as the results of previous LPI participants correspond to performance measures 
and can be used to predict leadership effectiveness. An external study of the LPI validity, using LISREL VII, found $t$ values greater than 7.0 for each category (Kouzes and Posner).

The reliability of the LPI has also been verified by internal and external analysis. Tests on the internal reliability have shown that the six questions in each category have a strong correlation. The reliability coefficients for the LPI-Self evaluation are between .75 and .87 in several studies that have been conducted (Kouzes and Posner 2002). The reliability coefficients for the LPI-Observer evaluation range between .88 and .92 (Kouzes and Posner). An internal study showed no significant change in results given within two months, demonstrating the test-retest reliability, and independent external studies consistently show a coefficient around .90 (Kouzes and Posner).

The completion of the LPI by the participants identified in the previous section provided both qualitative and quantitative data that is relevant to this study. The data collected assisted in the determination of emergent themes that answered RQ1 of this study: What are the leadership practices of a principal in a selected high school that has a high teacher retention rate in a region of West Virginia? Answers from the LPI also provided insight into RQ3: What contributes to a school culture that retains teachers in a selected high school that has a high teacher retention rate in a region of West Virginia?

The data from the LPI, which was given in conjunction with the interviews, allowed a comparison of the strength of the leadership practices of this principal, whose school had demonstrated a high rate of teacher retention, with the thousands of other leaders who have previously participated in the LPI study. Because the LPI is a confidential survey, it allowed the researcher insight into the basic underlying 
assumptions of school's members. While these underlying assumptions are often difficult to uncover within an organization's culture, they are paramount in understanding why certain things occur, and the effect that these occurrences have on members of the organization (Schein, 2004).

Apart from the 360-degree LPI instrument, the researcher also collected data through the study of school documents. The use of such documents was a means to "... ground an investigation in the context of the problem ...," as school records provided a summary of previous leadership practices and allowed an insight into the culture of the school (Merriam, 1988, p. 109). These artifacts are often easily noticed, but sometimes difficult to understand (Schein, 2004). The documents provided an idea of the everyday tasks and routines that occurred within the school, and allowed an overview of the values held by the members of the school community. Patton (2002) suggests the collection of "... all routine records on clients, all correspondence from and to program staff, financial and budget records, organizational rules, regulations, memoranda, charts, and any other official or unofficial documents generated by or for the program" (p. 293).

For use in this study, the researcher collected (a) written communications between the principal and board office personnel, school staff members, and parents, (b) student and faculty handbooks, (c) school memoranda, (d) demographic data of the school personnel, (e) meeting agendas and notes, and (f) any media accounts involving the school or personnel. Requests for communications and memoranda were limited to those that were relevant to the five defined practices of exemplary leaders: (a) modeling the way, (b) inspiring a shared vision, (c) challenging the process, (d) enabling others to act, and (e) encouraging the heart (Kouzes and Posner, 2003). Any archival information 
attained was used to “... gain valuable historical insights, identify potential trends, and explain how things got to be the way they are" (Gay, Mills, and Airasian, 2006, p. 422). The themes that emerged through the review of documents were useful in determining answers to:

RQ1. What are the leadership practices of a principal in a selected high school that has a high teacher retention rate in a region of West Virginia?

RQ3. What contributes to a school culture that retains teachers in a selected high school that has a high teacher retention rate in a region of West Virginia?

These documents provided a view of the artifacts that are a part of the school's culture, and demonstrated the emphasis that the principal places on certain aspects of leadership within the school.

The use of in-depth interviews was also used to address:

RQ1. What are the leadership practices of a principal in a selected high school that has a high teacher retention rate in a region of West Virginia?

RQ2. Why do teachers stay in a selected high school that has a high teacher retention rate in a region of West Virginia?

RQ3. What contributes to a school culture that retains teachers in a selected high school that has a high teacher retention rate in a region of West Virginia?

The researcher conducted a series of single interviews of the administration, both county and building-level, and the faculty members in order to collect data for this study. The interviewing process provided data that was essential for uncovering the espoused values of the school. These espoused values are those strategies, goals, and philosophies that the school members value (Schein, 2004). 
The nature of these interviews was open-ended, as the researcher developed an observational role within the school (Yin, 1984). These interviews provided data that allowed the researcher to develop an insider's understanding of the perceptions of those who function within the school (Miles \& Huberman, 1994).

Using the guidelines established by Patton (2002) for questioning, an interview guide was established to discern participants' insights into the areas of consideration that have been outlined in the research questions for this study. Sample interview questions were designed to be open-ended and correspond to the six types of questions identified by Patton: (a) experience and behavior, (b) opinions and values, (c) feeling, (d) knowledge, (e) sensory, and (f) background/demographic. 
Table 2

Distribution of Interview Questions for Leadership for Teacher Retention using Patton's (2002) Question Types across participants

Question $1 \quad$ What are the leadership practices of a principal in a selected high

school that has a high teacher retention rate in a region of West

Virginia?

Participant Type Interview Questions

School Staff E In what ways does the principal set an example of what he expects from others?

$\mathrm{K} \quad$ What is the vision of the school?

O What leadership practices are employed by the principal that you believe to be essential in creating the shared vision of the school?

$\mathrm{K}$ What methods of communication does the principal employ?

S What do you notice about the principal's role in the professional development of the faculty?

K What innovative instructional strategies does the principal encourage teachers to use in their classes?

E In what ways have you been able to participate in schoolbased decisions and activities? 
Table 2 (continued).

Participant Type Interview Questions

School Staff $\quad \mathrm{K} \quad$ What are the methods used by the principal to gather input from the faculty?

E In what ways has the principal rewarded you or recognized your work?

F What encouraging remarks have you heard the principal make toward other staff members or students?

B What is your experience in the field of education?

County Administrator $\mathrm{E} \quad$ What is your association with this school?

E In what ways does the principal set an example of what he expects from others?

$\mathrm{K} \quad$ What is the vision of the school?

O What leadership practices are employed by the principal that you believe to be essential in creating the shared vision of the school?

$\mathrm{K}$ What methods of communication does the principal employ?

$\mathrm{S}$ What do you notice about the principal's role in the professional development of the faculty?

$\mathrm{K}$ What innovative instructional strategies does the principal encourage teachers to use in their classes? 
Table 2 (continued).

Participant Type Interview Questions

County Administrator $\mathrm{E}$ In what ways have teachers been able to participate in school-based decisions and activities?

$\mathrm{K}$ What are the methods used by the principal to gather input from the faculty?

E In what ways has the principal rewarded the staff or recognized their work?

F What encouraging remarks have you heard the principal make toward staff members or students?

B What is your experience in the field of education?

Principal E In what ways do you set an example of what you expect from others?

$\mathrm{K} \quad$ What is the vision of the school?

O What leadership practices do you employ that you believe to be essential in creating the shared vision of the school?

$\mathrm{K} \quad$ What methods of communication do you employ?

$\mathrm{S} \quad$ What do you notice about your role in the professional development of the faculty?

$\mathrm{K}$ What innovative instructional strategies do you encourage teachers to use in their classes?

E In what ways have teachers been able to participate in school-based decisions and activities? 
Table 2 (continued).

Participant Type Interview Questions

Principal K What methods do you use to gather input from the faculty?

E In what ways have you rewarded the staff or recognized their work?

F What encouraging remarks have you made toward staff members or students?

B What is your experience in the field of education?

\begin{tabular}{|c|c|c|c|}
\hline \multirow[t]{2}{*}{ Key } & $\mathrm{E}=$ Experience/Behavior & $\mathrm{O}=$ Opinion/Values & $\mathrm{K}=\mathrm{K}$ nowledge \\
\hline & S=Sensory & $\mathrm{B}=$ Background/Demographic & \\
\hline
\end{tabular}


Table 3

Distribution of Interview Questions for Leadership for Teacher Retention using Patton's (2002) Question Types across participants

Question 2 Why do teachers stay in a selected high school that has a high teacher retention rate in a region of West Virginia?

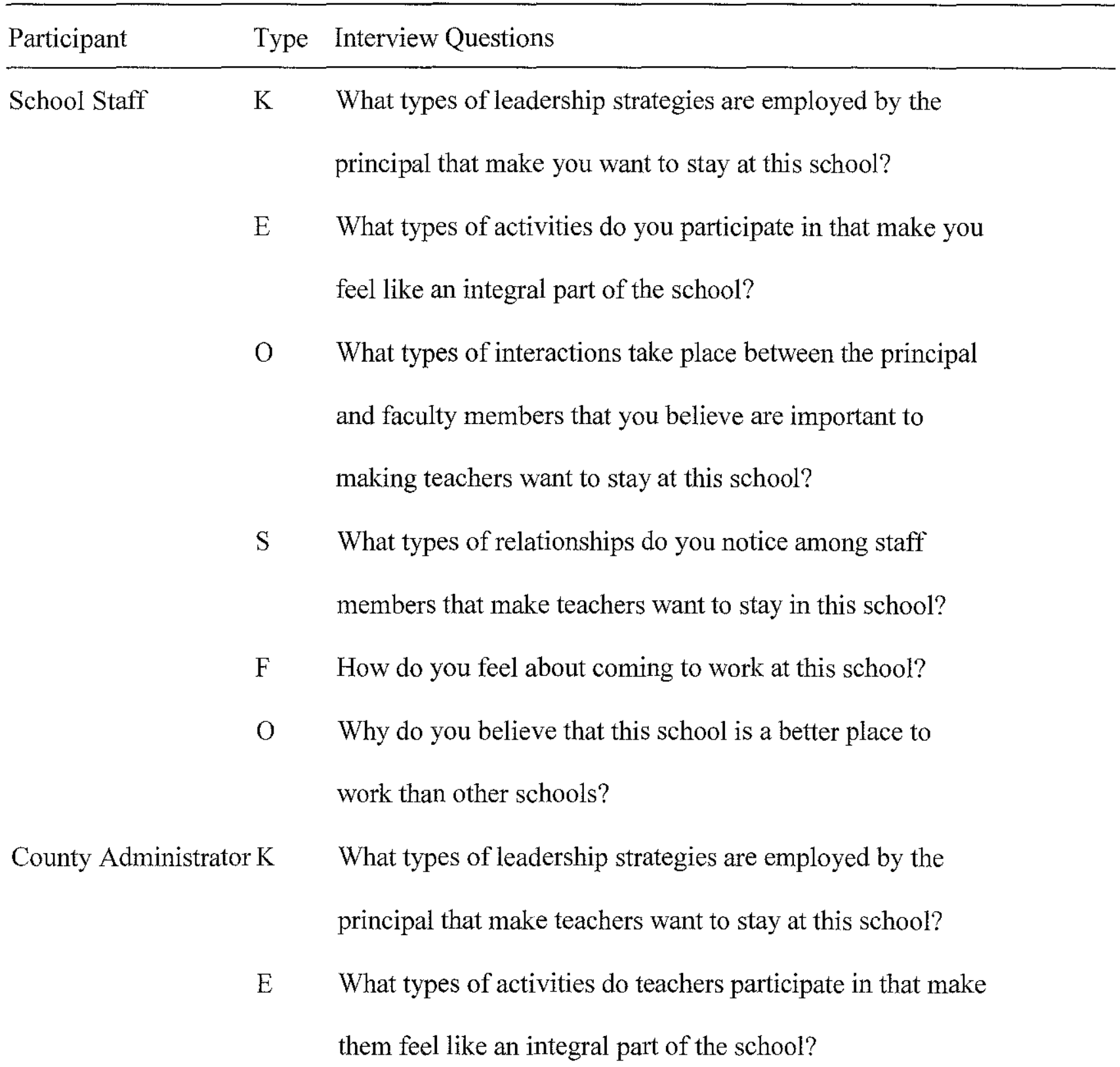


Table 3 (continued).

Participant Type Interview Questions

County Administrator $\mathrm{O}$ What types of interactions take place between the principal and faculty members that you believe are important to making teachers want to stay at this school?

S What types of relationships do you notice among staff members that make teachers want to stay in this school?

F How do you feel about working with this school?

O Why do you believe that this school is a better place to work than other schools?

Principal K What types of leadership strategies do you employ that make teachers want to stay at this school?

E What types of activities do teachers participate in that make them feel like an integral part of the school?

$\mathrm{O} \quad$ What types of interactions take place between you and faculty members that you believe are important to making teachers want to stay at this school?

S What types of relationships do you notice among staff members that make teachers want to stay in this school?

F How do you feel about coming to work at this school?

O Why do you believe that this school is a better place to work than other schools? 
Table 3 (continued).

$\begin{array}{lll}\text { Key } & \text { E=Experience/Behavior } & \mathrm{O}=\text { Opinion/Values } \quad \mathrm{F}=\text { Feeling } \quad \mathrm{K}=\text { Knowledge } \\ \mathrm{S}=\text { Sensory } & \mathrm{B}=\text { =Background/Demographic }\end{array}$


Table 4

Distribution of Interview Questions for Leadership for Teacher Retention using Patton's (2002) Question Types across participants

Question 3 What contributes to a school culture that retains teachers in a selected high school that has a high teacher retention rate in a region of West Virginia?

\begin{tabular}{|c|c|c|}
\hline Participant & Type & Interview Questions \\
\hline \multirow[t]{7}{*}{ School Staff } & $\mathrm{O}$ & $\begin{array}{l}\text { What cultural aspects of your school make it unique in } \\
\text { comparison to other schools? }\end{array}$ \\
\hline & $\mathrm{E}$ & $\begin{array}{l}\text { What experiences have helped create your perception of the } \\
\text { culture of this school? }\end{array}$ \\
\hline & $\mathrm{K}$ & $\begin{array}{l}\text { What beliefs about education are promoted among the } \\
\text { faculty and staff of the school? }\end{array}$ \\
\hline & $\mathrm{S}$ & What do you notice about the appearance of the school? \\
\hline & $\mathrm{O}$ & $\begin{array}{l}\text { How do you believe the principal creates a positive school } \\
\text { culture? }\end{array}$ \\
\hline & $\mathrm{F}$ & $\begin{array}{l}\text { What are your overall perceptions of the culture of the } \\
\text { school? }\end{array}$ \\
\hline & $\mathrm{F}$ & $\begin{array}{l}\text { What cultural conditions make you want to stay at this } \\
\text { school? }\end{array}$ \\
\hline \multicolumn{2}{|c|}{ County Administrator $\mathrm{O}$} & $\begin{array}{l}\text { What cultural aspects of this school make it unique in } \\
\text { comparison to other schools? }\end{array}$ \\
\hline
\end{tabular}


Table 4 (continued).

Participant

Type Interview Questions

County Administrator E What experiences have helped create your perception of the

culture of this school?

K What beliefs about education are promoted among the faculty and staff of the school?

$\mathrm{S} \quad$ What do you notice about the appearance of the school?

O How do you believe the principal creates a positive school culture?

F What are your overall perceptions of the culture of the school?

F What cultural conditions make teachers want to stay at this school?

Principal

$\mathrm{O}$ What cultural aspects of your school make it unique in comparison to other schools?

E What experiences have helped create your perception of the culture of this school?

$\mathrm{K}$ What beliefs about education are promoted among the faculty and staff of the school?

$\mathrm{S} \quad$ What do you notice about the appearance of the school?

O How do you believe you create a positive school culture?

F What are your overall perceptions of the culture of the school? 
Table 4 (continued).

\begin{tabular}{lll} 
Participant & Type & Interview Questions \\
\hline Principal & F & What cultural conditions make teachers want to stay at this \\
& & school?
\end{tabular}

\begin{tabular}{ll} 
Key E=Experience/Behavior & $\mathrm{O}=$ Opinion/Values $\quad \mathrm{F}=$ Feeling $\quad \mathrm{K}=$ Knowledge \\
$\mathrm{S}=$ =Sensory & $\mathrm{B}=$ Background/Demographic \\
\hline
\end{tabular}


The 360-degree LPI model; the study of school documents; and the interviewing of administration and faculty members provided triangulation that ensured the rigor of this study. These three data collection procedures provided reliability and validity as each of the three levels of organizational culture described by Schein (2004) were addressed: (a) artifacts, (b) espoused values, and (c) basic underlying assumptions. The utility and vitality of this research were established as the researcher seeks to provide data and conclusions relevant to the establishment of guidelines that are useful to local school leaders as they address the nation-wide dilemma of securing a retentive culture among the faculty of their schools. The researcher log and transcripts of interviews provided sufficient depth to ensure the verisimilitude of the research. Ethical guidelines for human subject research were followed at all times as confidentiality and anonymity were provided for all of those who participated in the study.

\section{Ethical Considerations}

Strict ethical guidelines were adhered to in order to assure the creation of a relevant qualitative study. "To a large extent, the validity and reliability of a study depend upon the ethics of the researcher" (Merriam, 2002, p. 29). Proper planning and preparation for ethical issues was secured to protect the integrity of the research, as well as the researcher and participants.

The researcher for this study completed the Institutional Review Board's for Protection of Human Research Subjects (IRB) training prior to conducting the research. All data collection and analysis procedures met the IRB requirements covered under the provisions of the Federalwide Assurance of West Virginia University. 
In order to protect the participants of this study, an informed consent was attained from everyone who participated in the LPI and interview process. The informed consent was essential in this case study as there was the possibility of professional risk, and the potential of unpleasant self-knowledge existed as a result of participation (Krathwohl, 1998). The researcher followed the guidelines established for informed consent presented by Patton (2002), which include defining (a) the purpose of the study, (b) the audience and use of the information, (c) the questions to be asked, (d) handling of the responses, and (e) the risks and benefits of participation. The confidentiality of the participants was ensured by assigning pseudonyms for each of the respondents and the selected school, and the privacy of the participants was assured.

The ethical guidelines established for this study protected the rights of those who chose to participate in the research. By following these ethical principles, the researcher assured that his own integrity, as well as that of the case study, was not compromised.

\section{Data Analysis Methods}

The LPI assessment was analyzed using a group percentile ranking offered by Fine Points Professionals, LTD. This report compared the self and observer scores of the selected principal to thousands of other leaders who have taken this assessment. Percentile scores were given for each of the five leadership practices defined by Kouzes and Posner (2009), allowing the comparison of the principal of the selected school to other leaders, nationwide. The results of the LPI assessment were used to determine emerging themes that were relevant to the first of the three research questions of this study. 
Grounded theory techniques were used to analyze the data from the open-ended interviews and document review. The phases of grounded theory described by Patton (2002) were utilized, which include: (a) basic description of data, (b) categorizing, and (c) theorizing. Interviews were recorded, transcribed, and thoroughly reviewed in order to determine emergent themes. The constant comparative method was used to code responses and define categories based on consistent themes found in the data. New indicators of each concept were sought out until saturation occurred (Krathwohl, 1998). Qualitative data analysis software, HyperResearch 3.0.2, was utilized to code and conduct the analysis of these data. Interviews were recorded and kept under lock and key. Transcripts of these interviews were made available to committee members as requested. Sealed notes and a researcher log were also maintained.

The involvement of teachers, and county administrators, as well as the school administration in the LPI 360 provided triangulation that ensured validity of this instrument. Furthermore, the evaluation of school documents and the interview process, in conjunction with the LPI, allowed triangulation within the research. Persistent observation, peer debriefing with a fellow administrator and members of the doctoral committee, the occurrence of member checks, as participants were provided the opportunity to review the interview transcripts, and an audit trail were used to further the validity of this case study.

\section{Summary}

Chapter One of this proposal defined the importance for this research in the area of creating a culture that is conducive to teacher retention within the public school. While there is a plethora of information that provides insight into the reasons that 
teachers are leaving, there is little research available to help school principals understand the reasons that teachers want to stay in their schools. The goal of this study was to discover emerging themes that answer the three research questions and provide relevant data in the area of creating a school culture that promotes teacher retention.

Chapter Two was a review of literature related to leadership and cultural aspects that may affect teacher retention rates. This chapter focused on pertinent issues regarding: (a) the chronology of leadership study, (b) practices of transformational leadership, (c) school leadership, (d) school culture, (e) teacher motivation, (f) teacher networks, and $(\mathrm{g})$ recent research in the area of creating a retentive culture. Recent research in the area of creating a retentive culture in schools has consistently noted the importance that teachers place on school leadership and culture as determining factors for staying in, or leaving, the classroom. The elements discovered through this review of literature emphasized the need for further qualitative research in the area of creating school cultures that lead to high teacher retention rates.

Chapter Three outlined the quantitative and qualitative methods that were employed to conduct this research. This chapter detailed: (a) the qualitative research design, (b) the retentive school culture from a qualitative perspective, (c) the researcher's perspective, (d) the selection criteria for the school to be studied, (e) the characteristics of the research site and participants involved in the study, (f) the Leadership Profile Inventory (LPI) instrument and procedures for data collection, $(\mathrm{g})$ ethical considerations, and $(\mathrm{h})$ the data analysis methods. The researcher's goal in chapter three was to illuminate, in detail, the methods that were used, and the reasons that these research methods were applicable to this case study. 


\section{Chapter Four: Results}

Chapter Four presents the results of the statistical data analysis for this mixed methods study. The results are organized into three sections: the LPI assessment, the open-ended interviews, and the document review.

The results of the LPI assessment are presented in quantitative form and include overall score comparisons between the principal, the principal's manager, and the school employees who report directly to the principal. Percentile rankings are presented for the principal in each of the five practices which Kouzes and Posner (2009) have identified with successful leaders: (a) model the way, (b) inspire a shared vision, (c) challenge the process, (d) enable others to act, and (e) encourage the heart. The purpose of the LPI assessment was to give a comparison of the principal to the thousands of other leaders who have participated in the LPI nationwide.

The results of the open-ended interviews and the document review broke down

the leadership practices and cultural elements of the school on a qualitative sense. These results are presented using the LPI framework of successful leadership practices, including themes that were revealed related to cultural elements of the school.

These three data collection procedures were used to answer the research questions:

RQ1. What are the leadership practices of a principal in a selected high school that has a high teacher retention rate in a region of West Virginia? RQ2. Why do teachers stay in a selected high school that has a high teacher retention rate in a region of West Virginia? 
RQ3. What contributes to a school culture that retains teachers in a selected high school that has a high teacher retention rate in a region of West Virginia?

\section{LPI Assessment}

The LPI questionnaire was given to the principal of the selected school, the superintendent of the school system, and the faculty of the school (which included the assistant principals and teachers). Questionnaires were returned by the principal, superintendent, and $67 \%$ of the school's faculty. The instrument included 30 behavioral statements, having six statements for each of the five practices. Each participant ranked the leader on an ordinal scale of one-to-ten for every behavioral statement, one meaning that the principal almost never engaged in the behavior and ten meaning that the leader almost always engaged in that behavior. The questionnaire took 10 to 20 minutes to complete. With the exception of the principal and superintendent, all of the questionnaire feedback was anonymous.

The following tables display the quantitative results of the LPI Assessment.

Table 5, shows the Data Summary for the LPI instrument, providing an overall score for the principal and superintendent, and a mean score of faculty feedback for each of the five practices. These total scores can range from 6 to 60 for each category. Table 6 , lists the rankings of each leadership behavior based on the mean of the observers' (faculty and superintendent) scores, and shows the comparison to the principals' self score. Table 7, compares the percentile rankings of the principal's self score, the superintendent's score, and the mean faculty score with the results of over 250,000 leaders who have taken the LPI assessment. 
Table 5

LPI Five Practices Data Summary

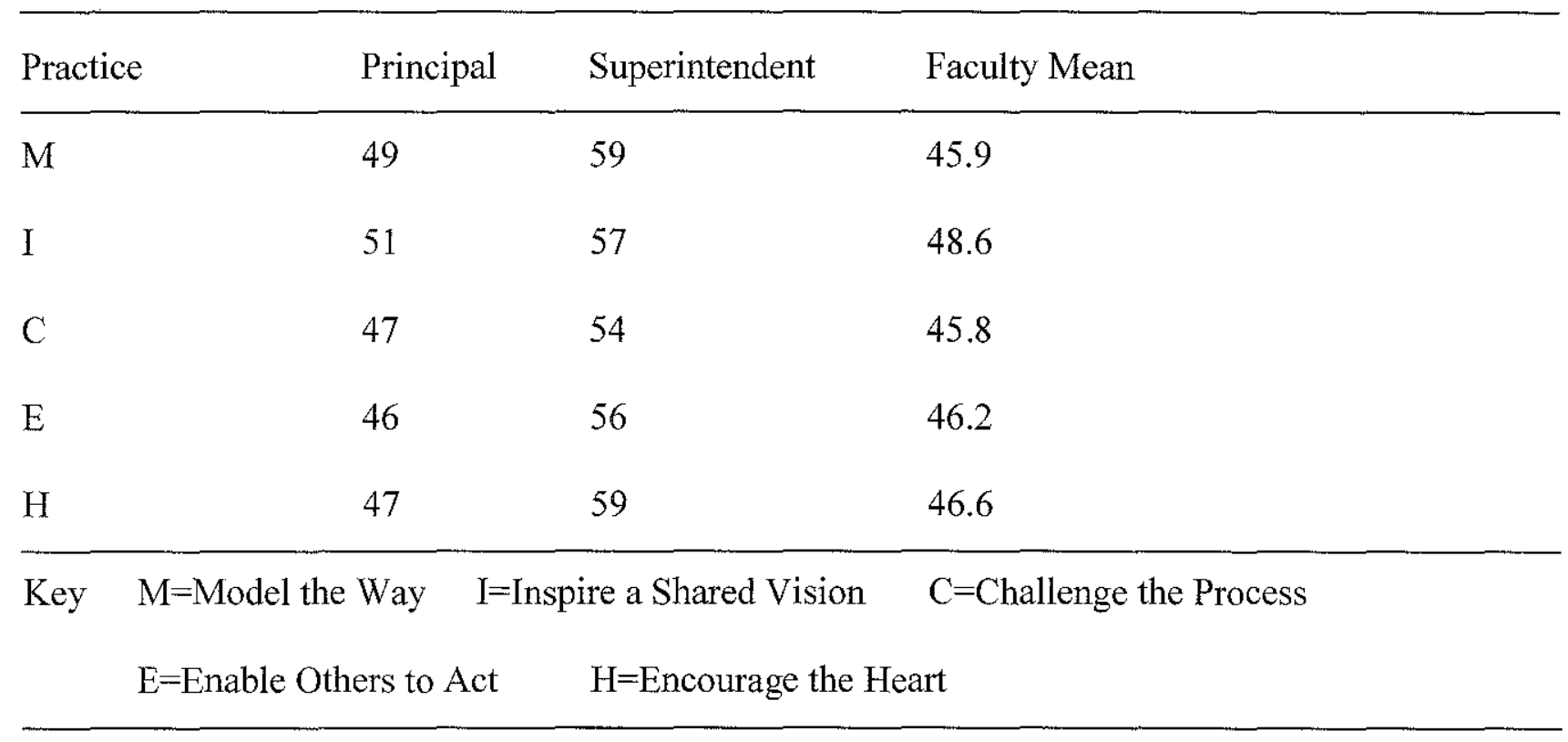


Table 6

\section{LPI Leadership Behaviors Ranking}

\begin{tabular}{llll}
\hline Behavior & $\mathrm{P}$ & $\mathrm{S}$ & $\mathrm{O}$
\end{tabular}

Talks about future trends influencing our work Inspire

9

8.6

Paints "big picture" of group aspirations

Inspire

9

8.6

Speaks with conviction about meaning of work

Inspire

8

Makes certain goals, plans, and milestones are set

Challenge 8

8.4

Is clear about his/her philosophy of leadership

Model

8

Recognizes people for commitment to shared valuesEncourage

Challenges people to try new approaches

Challenge $\quad 9$

Treats others with dignity and respect

Enable

9

8.1

Gives people choice about how to do their work

Enable

7

8.1

Follows through on promises and commitments

Model

Praises people for a job well done

Encourage

Describes a compelling image of the future

Inspire

Sets a personal example of what is expected

Model

Makes certain people adhere to agreed-on standards Model

Ensures that people grow in their jobs

Enable

7

Builds consensus around organization's values

Model

8

7.9

Finds ways to celebrate accomplishments

Encourage 7

7.9

Develops cooperative relationships

Enable

8

7.7

Searches outside for innovative ways to improve

Challenge

Gives team members appreciation and support

Encourage 8 
Table 6 (continued).

\begin{tabular}{|c|c|c|c|}
\hline Behavior & $\mathrm{P}$ & $\mathrm{S}$ & $\mathrm{O}$ \\
\hline Supports decisions other people make & Enable & 8 & 7.6 \\
\hline Expresses confidence in other people's abilities & Encourage & 8 & 7.5 \\
\hline Appeals to others to share dream of the future & Inspire & 9 & 7.4 \\
\hline Shows others how their interests can be realized & Inspire & 7 & 7.4 \\
\hline Seeks challenging opportunities to test skills & Challenge & 8 & 7.4 \\
\hline Creatively rewards people for their contributions & Encourage & 8 & 7.3 \\
\hline Experiments and takes risks & Challenge & 6 & 7.2 \\
\hline Asks "What can we learn?" & Challenge & 8 & 7.0 \\
\hline Actively listens to diverse points of view & Enable & 7 & 6.8 \\
\hline Asks for feedback on how his/her actions affect & Model & 6 & 5.8 \\
\hline people's performance & & & \\
\hline Key $\quad P=$ Practice & \multicolumn{3}{|c|}{$\mathrm{O}=$ Mean of Observers' Scores } \\
\hline
\end{tabular}


Table 7

LPI Percentile Rankings

\begin{tabular}{llll}
\hline Practice & Principal & Superintendent & Faculty Mean \\
\hline M & 58 & 99 & 41 \\
I & 76 & 95 & 65 \\
C & 54 & 87 & 45 \\
E & 27 & 87 & 27 \\
H & 46 & 96 & 44 \\
\hline
\end{tabular}

Key $\quad M=$ Model the Way $I=$ Inspire a Shared Vision $\quad \mathrm{C}=$ Challenge the Process

$\mathrm{E}=$ Enable Others to Act $\quad \mathrm{H}=$ Encourage the Heart 
The percentile rankings are divided into three levels based on a normal distribution curve. Scores falling in the first through $30^{\text {th }}$ percentiles are classified as low, scores between the $30^{\text {th }}$ and $70^{\text {th }}$ percentiles are moderate, and scores that fall between the $70^{\text {th }}$ and $99^{\text {th }}$ percentiles are considered high scores. The superintendent ranked the principal in the high range for each of the five practices. The principal's self scores and the mean of the faculty scores fell in the moderate range for all of the practices except Enable Others to Act. At the $27^{\text {th }}$ percentile for this behavior, for both the principal and faculty mean score, this ranking fell at the upper portion of the low percentile range of scores.

\section{Open-ended Interviews}

Participants in the open-ended interviews included the principal of the selected school, the superintendent of the school system, three assistant principals, and 16 faculty members. The 16 faculty members were chosen at random using an alphabetical list provided by the principal. Sixteen numbers were produced using a random number generator, and the faculty members that corresponded to those 16 positions on the list were asked to participate in the interview process. One teacher declined to participate, and was replaced by another faculty member who was selected using the same process. One assistant principal also declined to participate in the interviews, and was not replaced with another participant.

The mean years of experience for the participating faculty members was 15.25 years, with a range of seven to 36 years. The mean number of years that the participating faculty members have been at this selected school was 12.5 years, with a range of one to 36 years. The faculty members chosen to participate in the interviews included four 
mathematics teachers, four English teachers, two physical education teachers, two social studies teachers, two science teachers, one special education teacher, and one guidance counselor.

The major themes that arose during the course of the open-ended interviews included: (a) the principal allows teacher input on school-based decisions, (b) a family atmosphere exists among the staff, (c) the staff has a student-centered vision, (d) the principal communicates expectations, (e) the principal uses a variety of communication techniques, (f) the principal encourages innovative instructional strategies, $(\mathrm{g})$ the principal exhibits productive work habits, (h) the student body is well behaved, (i) the staff is supportive of one another, (j) the principal gives teacher recognition through announcements and faculty meetings, $(\mathrm{k})$ the staff builds community through faculty gatherings, and (1) the building is well maintained. These themes were determined using the constant comparative method during the analysis of the interview transcripts, and each of these themes included at least 20 coded passages.

The major theme that occurred with the greatest frequency, with a total of 80 references, was that the principal allows teacher input on school-based decisions. The principal acknowledged the importance "to involve, not only your administrative staff, but also the faculty and rest of your staff in making some decisions so that they buy in." There were 29 total references by those interviewed to the fact that staff members are allowed individual input by working directly with the administrative staff, piloting academic programs, and providing their opinions on school related matters. One teacher responded that the principal "has his core group, and he'll ask our opinions." There were 21 other references to the fact that teachers are able to provide input through serving on 
school committees. The principal stated that often times he uses the committees when there is an issue that he wants the faculty to "look at, research, and come up with a decision on." One faculty member stated that "everybody in the school is on a committee [and] each committee gets a chance to communicate in faculty senate meetings." Another teacher replied that the principal "is very good at involving the faculty in decisions involving deciding what the vision of the school should be, [using] different committees that every faculty member is on." Fifteen passages indicated that the principal uses the Curriculum Team, which consists of the department chairs, to share information and gather teacher input. The principal noted, "I take a lot of feedback from our departments through our department chairs and Curriculum Team." One staff member stated that these meetings allow teachers the "opportunity to voice any concerns." Another confirmed that teachers "have a lot of input in the Curriculum Team." There were 14 references to staff members having input through their participation in extra-curricular activities such as coaching athletics, sponsoring clubs, or through contributions in other areas. One teacher noted that the staff has participated in surveys to provide input on decisions such as discipline and health and wellness. Each of the 16 teachers and the three administrators interviewed referenced the fact that they, personally, have been afforded the opportunity to have input regarding school-based decisions.

The second theme that emerged during the analysis of the open-ended interviews, with a total of 40 references, is that a family atmosphere exists among the staff. Seventeen of these references used the term family to describe the relationships that are evident among the faculty and staff within the school. One staff member stated that the 
"high school is a family, and [the principal] is Poppa." This participant concluded that the reason he stays at the school is due to "the family atmosphere," mentioning that he has talked to teachers who have left the school, only to return because the camaraderie at the other school was lacking. Another participant noted that "we go out of our way, when we hire new people, to make them feel like part of the group." One teacher stated that "we encourage our young staff to come to [events] and get to know us outside of school." When describing the faculty, teachers noted that they "are caring and thoughtful people," and "they have good, strong relationships." One faculty member, who was once a student at this school, noted that being added to the faculty was "like going home again."

The third most frequently referenced theme was that the staff has a studentcentered vision, with a total of 34 passages. Each of the 16 staff members, who were interviewed, except for one, mentioned that the focus of the faculty was on the individual learning of each student. The principal stated, "I think that the majority of our staff truly believes that all students can learn. This is something that has evolved over time. But, now our faculty and staff do understand that all kids can learn, but it is at different levels and at different rates." One staff member stated that it was a school goal to "foster an environment in which young people can become successful. We want them to be successful academically, socially, and economically." Twelve of the 34 passages mentioned the intention of the staff to provide students with the skills necessary to be successful after high school. One participant noted that the staff recognizes the need "to prepare all students for their future beyond high school, whether it is a four-year school, a two-year school, or a trade. We want to prepare them for the workforce." 
The fourth theme, which received 32 references, is that the principal communicates expectations. Eight of these passages noted that the principal sets the goals for the school at the beginning of the year and revisits them frequently. One staff member stated, "He makes the vision very clear [and] in every faculty meeting we have, he mentions the goals and expectations that we have set for the year." Another mentioned that the principal "really outlines his expectations of [the staff] in the classroom, in the hallway, and anywhere else we are in the building." There were 15 references to the principal's communication and open dialogue with the staff. One participant made a statement regarding the interaction between the principal and staff, citing that "there's good dialogue between the principal and the teachers," and elaborated that much of this dialogue takes place at the faculty meetings. Six staff members mentioned that the principal is very forward when addressing teachers who are not meeting expectations, and that they appreciate this fact. The principal noted, himself, that he is very direct. One staff member pointed out that, "It's black and white. There is no middle. You understand what you are to do. If you don't, he's going to let you know. I like that." Commenting on the direct style of communication by the principal, another staff member stated, "You don't have to guess where you are in this organization, and that's a good feeling to have."

Two major themes included 27 coded passages. The first of these is that the principal uses a variety of communication techniques. The principal stated, "I use a variety [of ways to communicate], but the main one is face-to-face. I will send out emails. I'll drop a note in a teacher's box. I'll send out memos on letterhead. But, I'm more of the type that will go into a classroom and talk to a staff member face-to-face." 
Thirteen of the 27 passages referred to face-to-face communication as a primary means of interaction between the principal and the staff. One participant listed a variety of communication techniques that the principal employs, concluding that "he's more of a face-to-face person, though." The most frequently referenced form of communication, with 15 passages, was the use of email. One participant stated that the principal communicates with him most often through email. The other main forms of communication that were mentioned included: (a) 12 references to faculty meetings, (b) nine references to the use of announcements, and (c) six references to the use of notes or memos. Each of the participants acknowledged that the principal uses a variety of communication techniques, and that he is "good at keeping [the staff] informed."

The other theme that included 27 coded passages was that the principal encourages innovative instructional strategies. Eleven different instructional strategies or programs that the principal encourages were mentioned by the participants during the course of the interviews. These included: (a) ten references to technology integration, (b) ten references to APL strategies, which is a collection of classroom techniques that teachers use to ensure student understanding, (c) seven references to the strategies identified by Marzano, Pickering, and Pollock (2001), (d) six references to Bloom's Taxonomy and higher level questioning, and (e) three references to differentiated instruction. Teachers also noted that the school incorporates inclusive instruction for special education students, and one teacher referenced the school within a school program for at-risk freshmen. One teacher said that he appreciates the fact that "if [teachers] want to do things that are not conventional, [the principal] allows them to do it." One other participant made a statement regarding the principal's encouragement of 
innovation stating, "We are always trying to improve. There's no sitting back and resting on our laurels."

Two major themes garnered 26 coded passages. The first of these was that the principal exhibits productive work habits. Every staff member who was interviewed noted that the principal does an excellent job of demonstrating the professionalism that he insists on from the staff. One participant stated that "he sets the example and he expects us to follow it." Another noted that "he tries to reflect, through his work, how he wants teachers to be." Eleven of the 26 coded passages include the phrase, "He leads by example." The work habits that were of note to the staff included that the principal is: (a) prompt, (b) organized, (c) striving for perfection, (d) appreciative of his job, (e) active in the community, (f) professional, (g) positive, (h) honest, and (i) direct in his communication. One teacher stated that the faculty notices these qualities in their leader and "it rubs off on other people."

The other theme that received 26 references was that the student body is well behaved. The principal noted that one of the qualities of the school that he shares with every new teacher recruit is "we have a good student body." All three of the assistant principals and 12 of the 16 faculty members interviewed regarded the behavior of the students as a primary reason that they remain at the school. One teacher stated, "I stay because the students are awesome." Another expressed that the students "tend to demonstrate great maturity for their age." Four teachers noted that the behavior of the students allows for a positive culture in which students and staff feel safe.

Two themes received 25 references, placing them ninth in regards to the number of coded passages. The first of these was that the staff is supportive of one another. 
There were six references to teachers collaborating and sharing ideas. One of the teachers noted that "everyone wants everyone else to do well, so they are very supportive." Four teachers, and the principal, referenced the new teacher mentoring program that is in place within the school, and the support that is provided specifically for staff members who are new to the building. Three of the 16 teachers cited the support of the faculty as a major reason that they stay at the school. One teacher stated that "even though we don't have all the financial resources, the people resources are there."

The second theme that includes 25 coded passages was that the principal gives teacher recognition through announcements and faculty meetings. One staff member stated that the principal is "very complimentary when things are done well." Another said that the principal "is always praising people at faculty meetings [and] he uses examples of teachers that do things well." The county superintendent said, "I have attended faculty meetings [at the high school] when they were recognizing teachers. They celebrate their successes there." There were a total of 13 references to the principal recognizing teachers in front of the staff during faculty meetings. The principal asserted that "we try to celebrate successes, and if a teacher wins an award or has been recognized, we'll try to recognize them." He added that the announcements were the primary method he tried to use to acknowledge these teachers. There were five other references to the principal recognizing teachers using the morning announcements. Seventeen of the 21 people interviewed responded that the principal uses faculty meetings and announcements to recognize teachers. Four of the participants stated that they were recognized personally by the principal in the past. 
The eleventh major theme, with 21 coded passages, was that the staff builds community through faculty gatherings. There were 16 different faculty gatherings or activities that were mentioned during the interviews. One staff member noted that these types of activities "help you bond with other faculty." Participants expressed that attending these gatherings has helped foster friendships and build camaraderie. They described themselves as being "tight," "family," and "a very close group." The faculty gathering that was mentioned most frequently, with ten references, was the football game tailgate party. The superintendent noted that the faculty has been participating in the tailgate for the past 12 years. One participant associated the tailgate party with the "community feel" of the school. Overall, one teacher stated that the combination of all of these events "makes you feel like a welcome member of the team."

The final major theme was that the building is well maintained. This theme included 20 coded passages. The building is now 36 years old; yet, 20 of the 21 participants shared positive comments about the appearance and cleanliness of the school. The principal stated that "we all take pride in the way the building looks." One teacher complimented the custodial staff for doing "a nice job keeping the building clean and in good shape." One teacher described the building as "clean, welcoming, and inviting." Another claimed that "it looks professional." The superintendent praised the administration and staff for maintaining "a clean environment."

\section{Document Review}

Forty-one separate documents were collected and analyzed for the document review. Twenty-two of these documents were obtained from a binder that the principal maintains. He uses this binder to keep a record of written correspondence, and as a 
reference file of school events. The documents collected from this binder included: (a) copies of morning announcements, (b) faculty meeting agendas, (c) standardized testing schedules, (d) the staff schedule for the beginning of school, (e) semester exam schedules and instructions, (f) the school plan for Instructional Support days, (g) APL and Marzano instructional strategies, (h) the school's core beliefs and mission statement, (i) student meeting agendas, (j) the new teacher orientation agenda, (k) classroom management expectations, (1) a guidance counselors meeting agenda, (m) a curriculum team meeting agenda, (n) administrators meeting agendas, (o) letters to parents and faculty, and (p) the school supply list. The principal also provided copies of the student planner, student handbook, teacher handbook, and post cards he uses to congratulate staff members for exceptional work. Other documents found in the school included: (a) the library/media center flyer, (b) a student/athlete rules and policies pamphlet, (c) copies of parent newsletters, (d) calendars of school events, and (e) school newspapers. Two articles were acquired from the local newspaper. Three documents were found on the West Virginia Department of Education website, including: (a) the school report card, (b) a No Child Left Behind data report, and (c) a report of the state-wide standardized test results which compares the school data to county and state results.

The major themes that arose from the document review included: (a) the principal and staff have an academic focus, (b) the principal and staff teach students to be successful in and outside of school, (c) the principal and staff give student recognition, (d) the principal communicates expectations, (e) the principal continually strives for improvement, (f) the principal encourages innovative instructional strategies, (g) the principal gives teacher recognition, (h) the principal allows teacher input on school-based 
decisions, (i) the principal uses a variety of communication techniques, and (j) the school has high academic performance. These themes were determined using the constant comparative method throughout the document review. Each of the themes included at least 10 references.

The most frequently referenced theme throughout the document review was that the principal and staff have an academic focus. There were 42 examples of this theme in the documents reviewed. Each of the faculty meeting agendas include an academic focus such as "sharing of best practices" and "working together to focus on student learning, not just teaching." The teacher handbook encourages teachers to have "a focus that stresses curriculum and academics." The school has several programs that stress academics such as "Bring a Book, Take a Book," "Lunch and Learn," "Enrichment and Tutoring Activities," and the "After School Extended Learning Program." In a letter to the faculty, the principal states, "As always, I want our focus to be on academics." He reiterates this fact to the parents in one of the newsletters sent home. Several of the documents spelled out academic expectations for students, and the expectation of teachers to stress instruction and learning.

The theme with the second highest number of references was that the principal and staff teach students to be successful in and outside of school. There were 30 examples of this theme within the document review. The notions of success inside and outside of school are combined into one theme due to the frequent overlap within the coded passages. The student handbook states that the school "will provide the guidance and leadership needed to develop habits that will make an educated person a better citizen and human being," and emphasizes the belief that "learning is a life-long process." The 
student planner includes seven references to goal-setting, and preparing for success. Eight passages were found that refer to teaching students about citizenship and preparing them to be productive, respectful members of society. There are seven school programs referenced that assist students to be successful in the classroom, and teach skills necessary for the transition to post-secondary life.

The third major theme, with 20 references, was that the principal and staff give student recognition. The Student Outstanding Achievement Recognition (SOAR) program is "designed to recognize the academic/classroom efforts of [the school's] students." This program involves a quarterly awards ceremony in which students are recognized in front of their peers and parents. The school also awards honor roll students with academic letters. There were a total of 12 references to students who received recognition for curricular achievements. Eight passages involved recognition for extracurricular success. Students' successes in music programs, sports, drama, and business were addressed in parent newsletters and issues of the school newspaper.

The fourth most highly referenced theme, with 18 passages, was that the principal communicates expectations. Teacher expectations for classroom management, curriculum, and instructional strategies were outlined in eight separate passages. School procedures and expectations were covered in depth in the New Teacher Orientation agenda, and the principal provides all new staff with a document titled "Advice to New Teachers." One of the priorities identified in the teacher handbook is "open communication among administrators, faculty, and staff," and the expectation for administrators to "provide open lines of communication for all" is emphasized. 
The fifth major theme is that the principal continually strives for improvement. There were 17 references to this theme. The school has received a National High Schools that Work Pacesetter School Award, and the principal was recognized for his efforts in "improving school practices and raising student achievement." It was also noted that "the award reflects the school's efforts to improve instruction and learning." The principal, in his letters to the faculty and parents, stresses a focus "on issues that will improve student learning," and the school's goal "to improve student achievement." Faculty meeting agendas documented that the principal provides opportunities for "sharing of best practices," and discussions on "benchmark tests to improve WESTEST2 scores." The principal has initiated several programs within the building to "improve the quality of [students'] education, especially in the basic skills of reading, writing, and mathematics," and, in his letter to the faculty, stresses the need to "work together as a staff ... to realize our potential."

The sixth theme was that the principal encourages innovative instructional strategies, with 16 references. Marzano (2001) and APL strategies are given, in writing, to every teacher. Faculty meeting agendas documented discussions on differentiated instruction and collaborative techniques. In the parent letter, the principal states that there will be an emphasis on "reading across the curriculum," technology use, and "improving student learning [through] collaboration, standardized instruction, [and] formal and informal assessments." The school has a plan for student enrichment and remediation, and the principal provides staff development on effective instructional techniques. 
The seventh major theme, with 13 references, was that the principal gives teacher recognition. Each faculty meeting agenda documented that the principal publically recognizes teachers for exceptional work, and provided time for teachers to share successful instruction practices. The principal has post cards that he gives to teachers who are doing good things within the school. These cards read, "You're Terrific," "Superb Teaching!" and "You are Making a Difference." In parent newsletters, the librarian was recognized for her work over the summer, three teachers were mentioned for their efforts to make the school "a place that is inviting for all students and teachers," and the new faculty members were introduced. In an article from the local newspaper, the principal "thanked the faculty, staff, and students for a job well done." And, upon winning a national award from High Schools that Work, he attributed the award "to the efforts of the guidance counselors," when interviewed by the paper.

There are two themes that had 12 references in the documents reviewed. The first of these was that the principal uses a variety of communication techniques. The teacher handbook indicated that "information for teachers will be sent via school email, in the daily bulletin, or in administrative memos," and that "announcements will be read at 7:40 AM." There are "faculty meetings [which] are scheduled once a month, or as deemed necessary by the administration." Teachers are reminded of these meetings by announcement. The principal ensures "that information related to school and parent programs, meetings, and other activities is sent home to parents of participating children in a language that parents understand." The principal has documentation of information shared with parents through orientation meetings, supply lists, the school's NTouch program which sends emails and text messages, and the school's website. Teachers are 
made aware of weekly events through the Events Calendar, which is also available for the students and community.

The other major theme with 12 references was that the principal allows teacher input on school-based decisions. The student handbook noted that the principal will "provide for teacher, parent, and student input on school policies." The principal documented his incorporation of teachers who are pursuing administration degrees into daily administrative routines and the decision making process. The principal encourages teachers to "be active and involved," and to share their thoughts. There is documentation of faculty senate meetings, the senior steering committee, and curriculum team meetings in which teachers are involved in a variety of school-based decisions. Department-wide collaboration days are provided for teachers to discuss and make decisions about instruction and assessment.

The final theme was that the school has high academic performance. There were ten examples of the school's performance found in the documents which were reviewed. An article found in the local newspaper recognized the school for winning a national High Schools that Work (HSTW) Pacesetter School Award. This award is given to schools that "implement the HSTW design, teach students a rigorous curriculum linked to a specific program of high school study, maintain high achievement and completion rates, and meet Adequate Yearly Progress criteria of the federal No Child Left Behind Act of 2002." The school met Adequate Yearly Progress again in all areas for 2012, and was above the state and county proficiency levels in both Reading and Social Studies. The school's attendance rate of $97.48 \%$ is above the state average, and the graduation rate of $83.41 \%$ is above the county and state percentages. The school's average SAT scores in 
all three testing areas of math, critical reading, and writing are above the county averages, and the average composite score of 20.8 on the ACT is above both the county and state scores. The school has also been recognized for the number of students enrolled in Advanced Placement courses.

\section{Summary}

Chapter Four summarized the results of the LPI survey, the open-ended interviews, and the document review conducted for the school involved in this mixed methods study. The results of the LPI survey indicated that the principal is most adept in his ability to inspire a shared vision, while attaining the lowest scores in the area of enabling others to act. The open-ended interviews, though, contain numerous statements indicating that the participants have been provided significant influence in the process of school-based decisions. The document review substantiated this fact, as there were 12 references to the fact that the principal allows teacher input on school-based decisions. The open-ended interviews and document review both corroborated the LPI results which indicated that the principal communicates well with the staff, and inspires a school-wide vision and an academic focus.

There were several major themes that emerged through the open-ended interviews and the document review. The triangulation of the 360 LPI, the interviews, and document review provided a detailed representation of the leadership practices and cultural elements of the school in this study. Table 8 shows the major themes that emerged during the interviews, along with the total number of passages that corresponded to each theme. Table 9 displays the themes that emerged through the document review, 
and includes the number of references to each theme. Table 10 reveals the correlation between the quantitative and qualitative pieces of the study.

Table 8

Open-ended Interviews Emergent Themes

T $P$

Principal allows teacher input on school-based decisions $\quad 80$

A family atmosphere exists among the staff $\quad 40$

Staff has a student centered vision $\quad 34$

Principal communicates expectations $\quad 32$

Principal uses a variety of communication techniques $\quad 27$

$\begin{array}{ll}\text { Principal encourages innovative instructional strategies } & 27\end{array}$

$\begin{array}{ll}\text { Principal exhibits productive work habits } & 26\end{array}$

$\begin{array}{ll}\text { Student body is well behaved } & 26\end{array}$

Principal gives teacher recognition through announcements and faculty meetings 25

Staff is supportive of one another $\quad 25$

Staff builds community through faculty gatherings $\quad 21$

$\begin{array}{ll}\text { Building is well maintained } & 20\end{array}$

Key $\quad \mathrm{T}=$ Theme $\quad \mathrm{P}=$ Number of Passages 
Table 9

Document Review Emergent Themes

$\mathrm{T}$

$\mathrm{R}$

Principal and staff have an academic focus

Principal and staff teach students to be successful in and outside of school

Principal and staff give student recognition

Principal communicates expectations

Principal continually strives for improvement

Principal encourages innovative instructional strategies

Principal gives teacher recognition

Principal uses a variety of communication techniques

Principal allows teacher input on school-based decisions

School has high academic performance

Key $\mathrm{T}=$ Theme $\quad \mathrm{R}=$ Number of References 
Table 10

Thematic Overlap Between Qualitative Data and LPI Results

Theme Q Q L

Principal allows teacher input on school-based decisions

B E

A family atmosphere exists among the staff

OEI

Staff has a student centered vision

OEI

Principal communicates expectations

B I

Principal uses a variety of communication techniques

B I

Principal encourages innovative instructional strategies

B C

Principal exhibits productive work habits

OEI M

Student body is well behaved

OEI

Principal gives teacher recognition through announcements and faculty meetings $\mathrm{B} \quad \mathrm{H}$

Staff is supportive of one another

OEI

Staff builds community through faculty gatherings

OEI

Building is well maintained

OEI

Principal and staff have an academic focus

DR I

Principal and staff teach students to be successful in and outside of school

DR I

Principal and staff give student recognition

DR H

Principal continually strives for improvement

DR C

School has high academic performance

DR C 
There was one discrepancy with the LPI finding regarding the principal's ability to enable other to act and the themes found in the interviews and document review. Still, many of the major themes that emerged in the qualitative portions of the research overlap with, and substantiate the 360 LPI results. These major themes, and the similarities and differences that emerged generated the discussion in Chapter Five. 


\section{Chapter Five: Discussion}

Chapter Five presents the results of this research within the framework of the perspectives held by established experts in the field of organizational leadership.

Discussion is presented regarding the research questions:

RQ1. What are the leadership practices of a principal in a selected high school that has a high teacher retention rate in a region of West Virginia?

RQ2. Why do teachers stay in a selected high school that has a high teacher retention rate in a region of West Virginia?

RQ3. What contributes to a school culture that retains teachers in a selected high school that has a high teacher retention rate in a region of West Virginia?

The limitations of the study, implications in the field of school leadership and culture, and recommendations for future research are also presented.

\section{Practice of Leadership for Retention}

After spending numerous hours in the school, speaking to administrators and staff, and collecting documents, it has become apparent to the researcher that there are aspects of the principal's leadership style which make teachers want to work at this school. The principal demonstrates an understanding that everything he does influences this culture of teacher retention. It is evident that the principal has initiated and promoted a culture in which the students' interests are core. He sets the tone, communicates expectations, and models behaviors that he believes are essential to the field of education. His personal sacrifice and extended involvement in the school and community reveals an attitude of servant leadership that the teachers recognize and appreciate. 
Barnard (1938) believed that it is essential for leaders to instill a "real existence of a common [organizational] purpose" (p. 87). The principal of the school in this study has shown the ability to inspire a shared vision among the faculty. Both the principal and his staff rate him the highest in this practice of the LPI. It was noted by one faculty member that the principal "makes the vision very clear." Another teacher stated that the principal "has direct communication with us, telling us where we're going." One teacher, when asked why he stays at this school responded, "It's because you know the goals that [the principal] sets, and you know you can achieve those goals, and you believe in him. [The principal] has always done a good job of setting the goals, and telling us where we're going. He doesn't say, 'This is where we may go.' He tells us that we're going to get there, and what we're going to do to get there. We believe it. We buy into it. When we have problems, we break those down, and see what we need to fix to reach the goals."

Collins (1999) asserts that the vision of an organization should reflect its fundamental reason for existence, and in this school, it is apparent that the principal has supported an environment in which the well-being of the students is the focus. There was a consensus among the faculty interviewed that the vision of the school "is studentcentered learning," and that the faculty members "truly want the best for [their] kids." One teacher asserted, "We believe that we have a duty to educate every student. We have a duty to provide them the best possible education that we can. We have a duty to do our best on a daily basis." The fact that this concentration on students and academics is shared among the entire staff is paramount to the success of the school, and is a direct. result of the principal's attitude toward education. Kouzes and Posner (2007) express that shared visions "attract more people, sustain higher levels of motivation, and 
withstand more challenges than those that are singular" (p. 105). One teacher responded that he believed this school was a better place to work than other schools because, "We've been able to keep that high level of academics. [The principal] puts academics first, and he holds everybody accountable." In this school, it is clear to the researcher that the purpose to which the principal and staff adhere is to "provide each and every student with the opportunity for an excellent education."

In order to establish this shared vision, it is essential for a leader to be able to communicate effectively with the organization. In their research, Kouzes and Posner (2007) "found that expressing a vision is the most difficult of leadership skills" (p. 155). Speck (1999) expresses that building a vision "is very much an interactive process and depends heavily on two-way communication skills" (p. 37). The principal of this school excels in the area of communication. One teacher noted that the principal's "strongest asset is his ability to communicate with the staff." This same person stated that "a day doesn't go by that you don't know what is expected of you, and what's going on in the building." All of the teachers who were interviewed acknowledged that the principal uses a variety of methods for communication. The top three leadership behavior scores that the principal received in the LPI are all related to inspiring a shared vision through communication. These results indicate that he frequently: (a) talks about future trends influencing our work, (b) paints the "big picture" of group aspirations, and (c) speaks with conviction about the meaning of work. The principal's supervisor summarized that he "uses all the avenues" of communication in order to assure that every member of the organization remains "focused on a common goal to be the best." 
Not only has this principal created and communicated the shared vision, but the researcher noted that he also models the behaviors and productive work habits he expects from members of his faculty and staff. Speck (1999) asserts that a "principal's actions speak to the overall beliefs and expectations held for the school" (p. 38). All of the staff members who were interviewed recognized that the principal makes it a priority to "reflect, through his work, the way he wants teachers to be." Teachers acknowledged that the principal "leads by example" and "sets the precedence." Teachers commented on the principal's positive disposition, professional manner, organization, and honesty. One staff member noted that the principal "strives for perfection, and because of that, I think the teachers strive for perfection also. He sets the example and we go after it." One of the teachers expressed his appreciation that the principal "will educate himself about new practices and then have teachers employ those new practices. He actually knows the practices." He stated that this fact adds validity to vision that the principal has for the school.

As the principal and staff work toward the school's student-centered vision, the principal continually encourages teachers to employ innovative instructional strategies. During the time spent in this school, the researcher observed teachers incorporating technology, inclusion techniques, and cooperative learning. The researcher also observed the school within a school environment that the principal initiated to assist at-risk freshman students. Kouzes and Posner (2007) contend that "leadership is inextricably connected with the process of innovation, of bringing new ideas, methods, or solutions into use" (p. 165). The teachers who were interviewed and the documents reviewed indicated that there is a continual effort by the staff to master, initiate, and incorporate 
effective instructional strategies in order to benefit the students. This internal motivation to improve classroom instruction for the interest of the students is nurtured by the principal's focus on the academic well-being of the students. During faculty meetings, the researcher observed teachers addressing the faculty concerning unique instructional techniques that they were using successfully in their own classes. These teacher presentations were initiated by the principal. The researcher has observed the principal discussing the academic initiatives that are taking place in his school, as well as the enthusiasm he displays for academics. The principal has put on an Elvis wig and danced during a discussion of standardized test preparation in order to motivate staff, while at other times he has been blunt about the importance of finding the best methods for reaching students. Several teachers stated that one of the main reasons they stay at this school is the focus on academics. One teacher asserted that there is a feeling of safety, knowing that he is supported and encouraged to try "new things" in his classroom. The passion for academics and the pride that teachers take in the academic success of their school was evident to the researcher as teachers discussed the approaches that they take to assuring student preparation. This student-centered culture was accredited on numerous occasions to the emphasis on quality instruction that the principal instills.

While encouraging teachers to maintain high academic standards, and to utilize innovative instructional techniques in their own classroom, the principal also provides opportunities for teachers to help guide the direction of the school as a whole. Every participant in the interviews discussed the avenues that they have for providing input into the activities, staff-development sessions, and tasks that occur within the school. While the results of the LPI survey indicate that the principal does not ask for direct, one-on-one 
input from teachers on a regular basis, it became clear to the researcher that the principal has installed avenues for staff members to have their opinions recognized by the school's administration. Teachers noted that they are allowed input into seven of the ten areas in which Barth (as cited in Institute for Education Leadership, 2001) indicated that teachers should be actively involved. During the interviews, there was evidence that the school's staff is active in (a) choosing textbooks and instructional materials, (b) shaping the curriculum, (c) setting standards for student behavior, (d) deciding whether students are tracked into special classes, (e) designing staff development and in-service programs, (f) setting promotion and retention policies, and $(\mathrm{g})$ evaluating teacher performance. Much of this input is gathered through committees or the curriculum team, and many teachers may not recognize that the principal has provided these opportunities in order to allow their participation in setting school policies and procedures. One teacher noted, though, that through participation in the school committees, teachers "have a voice," and that his involvement has made him feel like an integral part of the school.

Finally, the principal has fostered an environment in which student and teacher recognition is elemental. The principal realizes that "verbal recognition of performance in front of one's peers and visible awards such as certificates, plaques, and other tangible gifts are powerful indeed and almost unlimited in their application" (Kouzes \& Posner, 2007 , p. 297). The principal uses faculty meetings and gatherings to recognize teachers for exceptional work. Upon entering the building, one of the first displays that catch a visitor's eye is the collection of pictures depicting the top ten students of each graduating class. The researcher observed several areas of the school that were used to present the awards and accomplishments of faculty and students which had been earned through 
curricular and extracurricular means. The documents reviewed for this study contained numerous citations of the excellence of both students and staff, and while conducting the interviews the entire staff continually complimented each other, the administration, and the students. The researcher noted the underlying pride that members of this faculty have in their school's achievements. Through his actions and comments the principal models the essential nature of taking pride in the school, and recognizing those who garner accolades for the school. The gratification projected by individual members of the faculty extends beyond personal recognition. When one member of the school experiences success, the faculty recognizes the value of that accomplishment for the entire school community. One staff member noted that the principal "is very complimentary when things are done well." Because of the high expectations that the principal holds for his staff, another participant explained that when you are recognized "it means all the more." All of the teachers who were interviewed discussed the avenues that the principal uses for teacher and student recognition. It is apparent to the researcher that this focus on showing gratitude toward others has permeated the school culture, and is manifested in the communication that the staff has regarding their colleagues and students.

During the time that the researcher spent in the school, several teachers expressed their concern that the principal of the school would eventually decide to further his professional career by taking a position at the central office. There was an underlying concern that if he were to leave, the sense of security that his leadership style provides would be in jeopardy. The teachers noted that "he bleeds [school colors]" and that he has his hands on every activity or initiative that takes place in the school. His love and 
passion for the school are contagious, and it was apparent that his attitudes foster an environment in which teachers enjoy coming to work. This principal embodies the transformational leadership style that Burns (as cited in Syque, 2008) establishes as a necessity for the maintenance of a culture that places the needs of the organization ahead of personal desires. One teacher noted that he lives on the other end of the county and graduated from a high school in that area; yet, when people ask him if he is going to go back to that school, he tells them, "This is my home."

It is the judgment of the researcher that the leadership practices of the principal have influenced a culture in which teachers feel safe and valued. This culture produces a familial bond among faculty and staff, creating a sense of home that teachers appreciate and in which they desire to remain.

\section{Reasons that Teachers Stay}

While the leadership practices of the principal have certainly influenced the teachers in this building, there are a wide variety of determining factors which affect the rate of teacher retention. Colleagues, school administration, and students all contribute to the reasoning of teachers who determine to stay at this school.

The researcher was greatly impressed with the sense of camaraderie that exists among the members of the faculty. Upon observing one of the faculty tailgate parties, which was mentioned with great frequency during the interviews, it became apparent to the researcher that the members of the faculty truly enjoy the companionship that is shared among the staff. The tailgate party was attended by numerous members of the staff, and the manner in which attendees conversed with one another, as well as with members of the community, revealed the existence of genuine relationships. Participants 
in the interviews also spoke of how the faculty has thrown baby showers, supported each other during the death or illness of family members, and assisted during times when they were ill. The depth of caring that these faculty members have for one another became especially apparent to the researcher while in attendance at the faculty and student volleyball game that was held as a fundraiser for a staff member whose son was ill. Teachers who were supervising the game spoke of their concern for this teacher and his family, and mentioned that similar events have been held in the past to assist staff members in need. The family atmosphere that the majority of the faculty spoke of is a substantial element of the school's culture. As one teacher explained, "people care about people here."

Another manner in which the faculty contributes to the high rate of teacher retention is through a unity in the school vision. All but one teacher participating in the interviews discussed the student centered focus of the school. They spoke, with pride, about the interventions that they employ to ensure the success of the students in their classes. It was apparent that in this school, staff and administrators value the educational process and the success of the students. These shared values allow members of the school community to feel as if they are a "part of the organization and that organizational life has important meaning" (Hoy \& Miskel, 2005, p. 167). The researcher observed the sense of satisfaction that the administration and staff felt over the academic and extracurricular accomplishments of their students. This staff believes that their school is the best in the area, and that with a continued focus on student preparation they will remain such. 
The principal also plays an influential role in maintaining a school climate that is conducive to teacher retention. He is able to allow teachers input in school procedures, which was the most frequently referenced theme during the staff interviews, while preserving his influence on all school related matters. He is so invested in the activities of the school that many staff members referred to him as a micro-manager. While in many instances this term could be considered negative, it appeared to the researcher that the staff of this school appreciated the fact that their leader was knowledgeable and involved in every aspect of school life. The principal recognizes his role as "the manager of the school, responsible for the legal, fiscal, and operational functions that provide an infrastructure for learning" (Fleck, 2005, p. 101). Because teachers believe that he will take responsibility for the administrative aspects within the building, it frees them to focus on their classrooms. One teacher mentioned that the principal's "attention to detail, at times micromanagement ... takes a lot of pressure off of other people [so] people can get their job done." The principal is able to balance his involvement so that his engagement in the school provides a sense of security that these teachers appreciate, while allowing them the input necessary to foster the staff's loyalty.

The teachers also respect the fact that the principal continually strives for excellence. He encourages the use of innovative instructional strategies, and pushes teachers to do their best every day. They are able to accept this pressure because he effectively communicates his expectations and models the types of behaviors and attitudes that he expects from others. The principal makes it a point to "demonstrate through personal example what it means to be passionately committed" (Kouzes \& Posner, 2007, p. 74). The teachers notice his involvement in staff development, his 
interaction with students, and his organization and attention to detail. The staff perceives his passion for the school and for education in general. Upon speaking to the principal, the researcher became acutely aware of the principal's desire to provide the best education possible for his students. He discussed teaching and guiding students, and "creating a learning atmosphere that benefits everybody." The principal's desire to have the best school, and willingness to work to achieve this goal, creates a sense of respect from the staff, and makes him a leader that teachers want to work with and work for.

The teachers also stay because of the students who attend this school. During the interviews, the teachers frequently complimented the behavior and work ethic of their students. Several teachers noted that the student body was one of the primary factors in their decision to remain at this school. Staff members in this building take great pride in the accomplishments of their students, and both the interviews and documents reviewed reveal that the young men and women who attend this school have achieved great success academically, in extracurricular events, and within the community. Upon interacting with several students in the building, the researcher was impressed with the students' personalities, behavior, and the respect they showed toward staff and other students. It is worth noting that this school, as with any school, has students who lack initiative and social awareness. Many staff members noted this fact, and the researcher observed students who were experiencing difficulties in these areas. The overwhelming majority of the students, though, are conscious to present themselves in a manner that reflects well upon themselves and their school. The teachers are able to enjoy their experiences at work, in large part, to the lack of behavioral issues from students, and this fact causes them to want to remain at this school. 
It is apparent to the researcher that the majority of teachers in this school truly believe that they work in the best school in the area. They enjoy the relationships that have been established with their colleagues, respect the school's leader, and love their students. These three elements of the school's internal community create a culture that fosters a desire among the staff members to continue their careers at this school.

\section{Culture is Everything}

Beginning with the trait theories, which arose during the era of classical organization theorists, the impact of leaders upon their subordinates has been noted. While neoclassical organization researchers, such as Barnard and Lewin, began the actual study of leadership practice, it wasn't until the Hawthorne Experiments, and resulting human relationship theories, that the impact of leadership upon organizational culture was exposed. The results of the subsequent research provided insight upon the practices that a leader can use to influence the culture of their organization. These transformational leaders affect a culture that provides a fulfilling work experience for individual members of the organization, while promoting the accomplishment of organizational goals.

The themes that emerged from the research conducted in this study upon a school that maintains a high rate of teacher retention in a specific region of West Virginia, led the researcher to infer that culture is everything in regards to retaining teachers. This school's stories and myths are passed on to new faculty members, as well as those in the community, in order to maintain the school's rich tradition and pride. Rituals are in place, which create a sense of predictability and safety. The researcher noted that the school's formal philosophy, as expressed in the vision and mission statements, directly 
related to the norms and espoused values that were expressed during the interviews, and reinforced with the document review.

The principal was cognizant of the cultural elements of his school. He understood his impact in the creation and maintenance of the school culture. While the faculty and student body had a great deal of influence on the overall school culture, it was the estimation of the researcher that the principal's behaviors and attitudes embedded the focus on students and sense of family that were present in his building. He displayed the transformational leadership characteristics promoted by Kouzes and Posner (2007); thus, fostering the fundamental cultural components necessary for teacher retention in his school.

The findings of this single case study are limited in their application. The results of any case study may not be generalized, and any inferences from this research should be framed in the context of this study. Still, the transferable notions of this model of leadership certainly have implications in the field of education. The profile of this school provides insight into the creation of a school culture that promotes teacher retention. The principal's leadership practices and the familial culture in the school offer ideals that may be transferable to other schools that are struggling to maintain staff members, and present questions that may be explored through further research.

\section{Recommendations for Further Research}

The research conducted in this study provided many emergent themes relevant to the creation of a school culture that promotes teacher retention. Due to the nature of this study, though, and the inability to generalize the results, further research regarding the phenomenon of teacher retention is needed. 
This study was conducted in the eastern panhandle of West Virginia, in an area that is known to compete for teachers among the states in close proximity. Each of the surrounding states offer pay packages which rank much higher than West Virginia's in the national standings. Therefore, further research should be conducted in schools with high teacher retention rates that exist in areas of West Virginia and the nation which are not competing with other states for teachers. This research may be used to determine the leadership practices and cultural elements which exist in schools where surrounding districts do not provide the opportunity for financial gain.

While this research focused on leadership practices and cultural elements in a school with a high rate of teacher retention, further research should be completed to discover any other themes which influence teachers to stay in their current positions. Influences outside of the school, such as a teacher's lifestyle, background, or simply their proximity to the school building may affect a teacher's reasoning to remain in their current teaching position. Research conducted in schools with both high and low rates of teacher retention may provide themes in areas other than school leadership and culture which increase the desire of a teacher to stay.

Finally, the results of the LPI leave questions regarding the external validity of the assessment within the field of education in regards to teacher retention. While the results of the survey fell primarily in the moderate level of percentile scores, the qualitative data demonstrate leadership practices that have affected a retentive culture in this school. Further research could help determine if the LPI is an effective measure of leadership practices that create a desire for teachers to stay in their current schools. 
Within the teaching profession, certain factors exist which influence teachers' desires to either leave or remain in their current teaching positions. While a great deal of study has been devoted to teacher attrition, further research is necessary in order to determine the factors that positively influence teacher retention. The research from this study has uncovered leadership practices and cultural elements of a school that may be used as a model for creating a culture that is conducive to teacher retention. The researcher believes that school leadership, staff, and students help shape the school culture, and influence teachers' dispositions to stay at their current schools. Future research can be conducted to further the understanding of teacher retention by determining:

1. Does school leadership and culture affect teacher retention in areas where surrounding districts do not provide the opportunity for financial gain?

2. Do factors other than school leadership and culture affect teachers' desires to stay in their current positions?

3. Is the LPI assessment a valid predictor of teacher retention within a school? This nature of further research can provide additional insights into teacher retention; increasing the ability of school systems to retain an experienced and motivated staff, which is vital to maximizing the educational potential of our nation's students. 


\section{References}

Allen, G. (1998). Leading. Supervision. Retrieved from http://ollie.dcccd.edu/mgmt1374/book_contents/4directing/leading/lead.htm Alliance for Excellent Education (2005, August). Teacher attrition: A costly loss to the nation and to the states. Retrieved from http://www.all4ed.org/files/archive/publications/TeacherAttrition.pdf.

Bailey, W. J. (1991). School-site management applied. Lancaster, PA: Technomic Publishing Company.

Barnard, C. I. (1938). Functions of the executive. Cambridge, MA: Harvard University Press.

Barth, R. S. (2001, February). Teacher leader. In Institute for Educational Leadership. (2001, April). Leadership for student learning: Redefining the teacher as leader. Retrieved from http:/www.iel.org/programs/21st/reports/teachlearn.pdf.

Bartholomew, B. (2007, April). Why we can't always get what we want. Phi Delta Kappan, 88(8), $593-598$.

Berry, B. (2005, December). Recruiting and retaining board-certified teachers for hard-to-staff schools. Phi Delta Kappan, 87(4), 290 - 297.

Blanson, A. L. (2005). A case study of teacher retention at one urban school district. (Doctoral dissertation, Texas A\&M University, 2005).

Bolman, L. G., \& Deal, T. E. (1997). Reframing organizations: Artistry, choice, and leadership ( $2^{\text {nd }}$ ed.). San Francisco: Jossey-Bass, Inc. 
Buchanan. M., Bleicher, R. E., Behshid, S., Evans, C., \& Ngarupe, L. (2007). Ensuring teacher retention in a PDS. Paper presented at the Annual Meeting of the National Association of Professional Development Schools. Las Vegas, NV: Authors. (ERIC Document Reproduction Service No. ED497416)

Budig, G. A. (2006, October). A perfect storm. Phi Delta Kappan, 88(2), 114-116. Burns, J. M. (1978). Leadership. New York: Harper \& Row.

Charlotte Advocates for Education (2004, February). Role of principal leadership in increasing teacher retention: Creating a supportive environment. Charlotte, $\mathrm{NC}$ : Author.

Clayton, D. G. C., \& Schoonmaker, F. (2007, June). What holds academically able teachers in the profession? A study of three teachers. Teachers and Teaching: Theory and Practice, 13(3), 247-267.

Collins, J. (1999). Aligning action and values. In Hesselbein, F., \& Cohen, P. M. (Eds.), Leader to leader: Enduring insights on leadership from the Drucker Foundation's award-winning journals (pp 237 -245). San Francisco: Jossey-Bass Publishers.

Cottrell, D. (2008). Leadership energy $\left(E=m c^{2}\right):$ A high-velocity formula to energize your team, customers, and profits. Dallas: Cornerstone Leadership Institute. Cresell, J. W. (1998), Qualitative inquiry and research design: Choosing among five traditions. Thousand Oaks, CA: Sage Publications, LTD.

Dance, F. E. (1988). Introduction to communication. In Carmichael, C. W., Botan, C. H., \& Hawkins, R. (Eds.), Human communication and the aging process (pp 9-19). Prospect Heights, IL: Waveland Press, Inc. 
David, J. L. (2008, May). What research says ... small learning communities. Educational Leadership, 84-85.

Deal, T. E., \& Kennedy, A. A. (1982). Corporate cultures. Reading, MA: AddisonWesley.

Drucker, P. F. (1999). In Hesselbein, F., \& Cohen, P. M. (Eds.), Leader to leader: Enduring insights on leadership from the Drucker Foundation's award-winning journals (pp $3-7$ ). San Francisco: Jossey-Bass Publishers.

Fayol, H. (1916). General principles of management. In Shafritz, J. M., Ott, S. O., \& Jang, Y. S. (Eds.), Classics of organizational theory (6 $6^{\text {th }}$ ed.) (pp $\left.48-60\right)$. Belmont, CA: Thomson Wadsworth.

Fitzpatrick, A. (2001). School improvement through teacher decision making. Retrieved from Northwest Regional Educational Laboratory website: http://www.nwrel.org/sepd/sirs/8/s030.html.

Fleck, F. (2005). What successful principals do! 169 tips for principals. Larchment, NY: Eye on Education, Inc.

Flick, U. (1998). An introduction to qualitative research. Thousand Oaks, CA: Sage Publications, LTD.

Fiedler, F. E. (1996). Research on leadership selection and training: One view of the future. Administrative Science Quarterly, 41, 241-250.

Fulton, K., Burns, M., \& Goldenberg, L. (2005, December). Teachers learning in networked communities: The TLINC strategy. Phi Delta Kappan, 87(4), $298-303$. 
Gay, L. R., Mills, G. E., \& Airasian, P. (2006). Educational research: Competencies for analysis and applications ( $8^{\text {th }}$ ed.). Upper Saddle River, NJ: Pearson Education, Inc.

Glatthorn, A. A., \& Joyner, R. L. (2005). Writing the winning thesis or dissertation: A step-by-step guide ( $2^{\text {nd }}$ ed.). Thousand Oaks, CA: Corwin Press.

Glesne, C. (2003). Becoming qualitative researchers: An introduction $\left(3^{\text {rd }} \mathrm{ed}\right.$.). New York: New York University Press.

Goodwin, D. K. (1999). Ten lessons from presidents. In Hesselbein, F., \& Cohen, P. M. (Eds.), Leader to leader: Enduring insights on leadership from the Drucker Foundation's award-winning journals (pp 25 - 36). San Francisco: Jossey-Bass Publishers.

Haberman, M., \& Richards, W. (1990). Urban teachers who quit: Why they leave and what they do. Urban Education, 25(3), 297-303.

Hanson, S., \& Moir, E. (2008, February). Beyond mentoring: Influencing the professional practice and careers of experienced teachers. Phi Delta Kappan, 89(6), $453-459$.

Hennessy, S., Ruthven, K., \& Brindley, S. (2005). Teacher perspectives on integrating ICT into subject teaching: Commitment, constraint, caution, and change. Journal of Curriculum Studies, 37(2), $155-192$.

High Schools That Work. (n.d.). Site action planning workbook for $21^{\text {st }}$ century model HSTW sites. Atlanta, GA: Southern Regional Education Board.

Hoy, W. K., \& Miskel, C. G. (2005). Educational administration: Theory, research, and practice $\left(7^{\text {th }}\right.$ ed.). New York: McGraw-Hill. 
Ingersoll, R. M. (2012, May). Beginning teacher induction: what the data tell us. Education Week. Retrieved from http:/www.edweek.org/ew/articles/2012/05/16/kappan_ingersoll.h31.html

Institute for Educational Leadership. (2001, April). Leadership for student learning: Redefining the teacher as leader. Retrieved July 2, 2008, from http:/www.iel.org/programs/21st/reports/teachlearn.pdf.

Katz, M. B. (2001). The irony of early school reform: Educational innovation in mid nineteenth century Massachusetts. New York: Teachers College Press.

Kelleher, H. (1999). The best lesson in leadership. In Hesselbein, F., \& Cohen, P. M. (Eds.), Leader to leader: Enduring insights on leadership from the Drucker Foundation's award-winning journals (pp 43 - 50). San Francisco: Jossey-Bass Publishers.

Kennedy, M. M. (2005). Inside teaching: How classroom life undermines reform. Cambridge: Harvard University Press.

Kouzes, J. M. \& Posner, B. Z. (2002, May). The leadership practices inventory: Theory and evidence behind the five practices of exemplary leaders. Retrieved from http://www.leadershipchallenge.com/UserFiles/lc_jb_appendix.pdf

Kouzes, J. M., \& Posner, B. Z. (2003). Leadership practices inventory ( $\left.3^{\text {rd }} \mathrm{ed}.\right)$. San Francisco: Pfeiffer.

Kouzes, J. M., \& Posner, B. Z. (2007). The leadership challenge $\left(4^{\text {th }}\right.$ ed.). San Francisco: Jossey-Bass. 
Kouzes, J. M., \& Posner, B. Z. (2009). The leadership challenge: The most trusted source for becoming a better leader. John Wiley \& Sons, Inc. Publisher. Retrieved from http://www.leadershipchallenge.com/WileyCDA/Section/id-131089.html.

Krathwohl, D. R. (1998). Methods of educational and social science research: An integrated approach ( $2^{\text {nd }}$ ed.). Long Grove, IL: Waveland Press, Inc.

Lezotte, L. W., \& McKee, K. M. (2002). Assembly required: A continuous school improvement system. Okemos. MI: Effective School Products, Ltd.

Martin, J. (2002). Organizational culture: Pieces of the puzzle. In Shafritz, J. M., Ott, S.O., \& Jang, Y. S. (Eds.), Classics of organizational theory ( $6^{\text {th }}$ ed.) (pp $393-$ 414). Belmont, CA: Thomson Wadsworth.

Marzano, R.J., Pickering, D.J., \& Pollack, J.E. (2001). Classroom instruction that works: Researched-based strategies for increasing student achievement. Alexandria, VA: Association for Supervision and Curriculum Development.

Maslow, A. H. (1943). A theory of human motivation. In Shafritz, J. M., Ott, S.O., \& Jang, Y. S. (Eds.), Classics of organizational theory $\left(6^{\text {th }}\right.$ ed.) (pp $167-$ 178). Belmont, CA: Thomson Wadsworth.

McGrail, E. (2006, June). It's a double-edged sword, this technology business: Secondary English teachers' perspectives on a schoolwide laptop technology initiative. Teachers College Record, 108(6), 1055-1011.

McGregor, D. M. (1957). The human side of enterprise. In Shafritz, J. M., Ott, S. O., \& Jang, Y. S. (Eds.), Classics of organizational theory $\left(6^{\text {th }}\right.$ ed.) (pp $\left.179-184\right)$. Belmont, CA: Thomson Wadsworth. 
McKee, K. L. (2003). A study of factors related to teacher retention. (Master's thesis, University of North Texas).

Merriam, S. B. (1988). Case study research in education: A qualitative approach. San Francisco, CA: Jossey-Bass Inc.

Merriam, S. B. (Ed.). (2002). Qualitative research in practice: Examples for discussion and analysis. San Francisco, CA: Jossey-Boss.

MetLife. (2012). The MetLife survey of the American teacher: Challenges for school leadership. Retrieved from https:/www.metlife.com/assets/cao/foundation/MetLife-Teacher-Survey2012.pdf

Miles, M. B., \& Huberman, A. M. (1994). Qualitative data analysis ( $2^{\text {nd }}$ ed.). Thousand Oaks, CA: Sage Publications, Inc.

Mintzberg, H. (1983). The power game and the players. In Shafritz, J. M., Ott, S. O., \& Jang, Y. S. (Eds.), Classics of organizational theory (6 $6^{\text {th }}$ ed.) (pp $\left.334-341\right)$. Belmont, CA: Thomson Wadsworth.

National Association of Secondary School Principals. (2006). Breaking ranks in the middle: Strategies for leading middle level reform. Reston, VA: Author.

National Commission on Teaching and America's Future. (2002, August). Unraveling the "teacher shortage" problem: Teacher retention is the key. Symposium of the National Commission on Teaching and America's Future and NCATF State Partners. Washington D.C. Retrieved from http://www.ncsu.edu/mentorjunction/text_files/teacher_retentionsymposium.pdf. 
National Education Association. (2003). Teacher shortage fact sheet. Retrieved from http:/www.nea.org/teachershortage/03shortagefactsheet.html.

Nelson, B. (1999). Creating an energized workplace. In Hesselbein, F., \& Cohen, P. M. (Eds.), Leader to leader: Enduring insights on leadership from the Drucker Foundation's award-winning journals (pp 265 - 274). San Francisco: Jossey-Bass Publishers.

NetMBA. (2002). Herzburg's motivation theory: (Two factor theory). Retrieved from http:/www.netmba.com/mgmt/ob/motivation/herzberg/.

Niese, T. (2007, April). Why teacher networks (can) work. Phi Delta Kappan, 88(8), $605-610$.

Patton, M. Q. (2002). Qualitative research and evaluation methods $\left(3^{\text {td }}\right.$ ed.). Thousand Oaks, CA: Sage Publications, Inc.

Pennell, J. A., \& Firestone, W. A. (1998, January). Teacher-to-teacher professional development through state-sponsored networks. Phi Delta Kappan, 79(5), 354 357.

Penuel, W. R., \& Riel, M. (2007, April). The 'new' science of networks and the challenge of school change. Phi Delta Kappan, 88(8), $611-615$.

Perrachione, B. A., Rosser, V. J., \& Peterson, G. J. (2008, Fall). Why do they stay? Elementary teachers' perceptions of job satisfaction and retention. The Professional Educator, 32(2), $25-41$.

Peshkin, A. (1988, October). In search of subjectivity: One's own. Educational Researcher 17(7), $17-21$. 
Roberts, C. M. (2004). The dissertation journey: A practical and comprehensive guide to planning, writing, and defending your dissertation [Electronic version]. Thousand Oaks, CA: Corwin Press. Retrieved from http://books.google.com/books?id=rNpbcZULw4wC\&pg=PA\&130dq=dissertatio $\mathrm{n}+$ organization + of + the + study\&source $=$ web\&ots $=$ YefXS1w2c\&sig=LTRvP7gpmOrtas9Tx4LKA\&hl=en\&sa=X\&oi=bookresult\&resnum=4\&ct=result $\#$ PPT1,M1.

Roethlisberger, F. J. (1941). The Hawthorne Experiments. In Shafritz, J. M., Ott, S. O., \& Jang, Y. S. (Eds.), Classics of organizational theory (6 $6^{\text {th }}$ ed.) (pp $\left.158-166\right)$. Belmont, CA: Thomson Wadsworth.

Saphier, J. (2005). Masters of motivation. In Dufour, R., Eaker, R., \& Dufour, R. (Eds.), On common ground: The power of professional learning communities (pp $85-$ 113). Bloomington, IN: Solution Tree.

Schein, E. H. (1993). Defining organizational culture. In Shafritz, J. M., Ott, S. O., \& Jang, Y. S. (Eds.), Classics of organizational theory (6 $6^{\text {th }}$ ed.) (pp $\left.360-367\right)$. Belmont, CA: Thomson Wadsworth.

Schein, E. H. (2004). Organizational culture and leadership. San Francisco, CA: Jossey Bass Publishers.

Schlechty, P. C. (2001). Shaking up the school house: How to support and sustain educational innovation. San Francisco: Jossey-Bass, Inc.

Sergiovanni, T. J. (2001). The principalship: A reflective practice perspective $\left(4^{\text {th }}\right.$ ed.). Needham Heights, MA: Allyn \& Bacon. 
Shafritz, J. M., Ott, S. O., \& Jang, Y. S. (Eds.). (2005). Classics of organizational theory ( $6^{\text {th }}$ ed.). Belmont, CA: Thomson Wadsworth.

Soltis, J. F. (1984, December). On the nature of educational research. Educational Researcher, 13(10), $5-10$.

Southwest Educational Development Laboratory. (1992). Leadership characteristics that facilitate school change. Austin, TX: Author. Retrieved from http:/www.sedl.org/change/leadership/history.html

Speck, M. (1999). The principalship: Building a learning community. Upper Saddle River, NJ: Prentice-Hall, Inc.

Spellings hears tales of low teacher morale while visiting West Virginia. (2008, March 8). The Journal, p. B5.

Stake, R. E. (1995). The art of case study research. Thousand Oaks, CA: Sage Publications.

Stevenson, Jr., Z., Dantley, S. J., \& Holcomb, Z. J. (1999, Summer). Factors influencing the retention of mathematics and science teachers in urban systematic initiative school districts: Administrative perspectives. The Journal of Negro Education, $68(3), 442-450$

Syque. (2008). Burns' transformational leadership theory. Retrieved from http://changingminds.org/disciplines/leadership/theories/ burns_transformational.htm.

Taylor, F. W. (1916). The principles of scientific management. In Shafritz, J. M., Ott, S. O., \& Jang, Y. S. (Eds.), Classics of organizational theory (6 $6^{\text {th }}$ ed.) (pp 61 72). Belmont, CA: Thomson Wadsworth. 
United States Department of Education. (2002). No Child Left Behind, Retrieved from http:/www.ed.gov/nclb/landing.jhtml

United States Department of Education, National Institute of Education Sciences, National Center for Education Statistics (2010). Fast facts: Teacher trends. Washington, D.C.: Author. Retrieved from http://nces.ed.gov/FastFacts/display.asp?id $=28$

Van Wagner, K. (2008). Leadership theories: Eight major leadership categories.

Retrieved from http:/psychology.about.com/od/leadership/p/leadtheories.htm?p=1.

Van Wagner, K. (2008). Lewin's leadership styles: Three major leadership styles.

Retrieved from http:/psychology.about.com/od/leadership/a/leadstyles.htm?p=1.

Weber, M. (1947). The theory of social and economic organization (T. Parsons, Trans.). New York: Free Press.

Weld, J. (1998, March). Attracting and retaining high-quality professionals in science education. Phi Delta Kappan, 79(7), 536- 539.

West Virginia Department of Education. (2006). 2006 educational personnel data report. Charleston, WV: Author. Retrieved from http://wvde.state.wv.us/certification/educator/personneldata/2006_Personnel Data_Report.pdf.

West Virginia Department of Education. (2007). State superintendent's report on West Virginia's teacher shortage: A focus on mathematics, science, and world language. Charleston, WV: Author. 
West Virginia Department of Education. (2008). Title 126 legislative rule, Board of Education, series 136: Minimum requirements for the licensure of professional/paraprofessional personnel and advanced salary classifications (5202). Charleston, WV: Author.

West Virginia Department of Education. (2009). 2008 educational personnel data report. Charleston, WV: Author. Retrieved from http:/wvde.state.wv.us/certification/educator/personneldata/2008_Personnel_ Data_Report.pdf

West Virginia Department of Education. (2012). NCLB data for school year 2011-12.

Charleston, WV: Author. Retrieved from

http:/wveis.k12.wv.us/nclb/public12/replistd3.cfm?sy=12\&year=12\&xrep=0\&cn $=004 \& \mathrm{school}=501 \& \mathrm{sn}=501 \&$ coname $=$ BERKELEY\&rpage $=$ index.cfm $\&$ rptnum $=$ $11 \mathrm{~b} 12$

West Virginia Department of Education. (2012). NCLB report card. Charleston, WV: Author. Retrieved from http:/wveis.k12.wv.us/nclb/pub/rpt1011/cache/S00450111.pdf

West Virginia Department of Education. (2012). WESTEST2/APTA graphical assessment data. Charleston, WV: Author. Retrieved from http:/wveis.k12.wv.us/nclb/pub/Assessment/graph_level.cfm?sy=12\&year=12\&c $\mathrm{n}=004 \& \mathrm{sn}=501$ 
Wexford-Missaukee ISD Effective School Toolkit. (n.d.). Three-minute walk through.

Retrieved from

http://web.wmisd.org/General\%20Educations/toolkit/walkthroughs/Materials $\% 20$

for $\% 20$ Introducing $\% 20$ Walkthroughs/Walk\%20Through\%20Handout.pdf

Wikipedia. (n.d.). Retrieved from

http:/en.wikipedia.org/wiki/Transformational_leadership

Wineburg, S., \& Grossman, P. (1998, January). Creating a community of learners among high school teachers. Phi Delta Kappan, 79(5), 350-353.

Yin, R. K. (1984). Case study research: Design and methods. Beverly Hills, CA: Sage Publications Inc.

Zhou, L. (n.d.). Book review on: The function of the executive. [Review of the book The function of the executive]. Retrieved from http://som.yale.edu/faculty/Sunder/PhdAccountingControl/BarnardReviewLing.doc 
APPENDIX A

Request for school participation

\section{(Date)}

\section{(School address)}

Dear (Principal's name):

Having contacted your Superintendent, he is aware that I am seeking your assistance with my research study. My name is Ron Branch and I am writing to request your school's participation in a case study whose purpose is to examine the leadership practices and cultural aspects of schools that have high teacher retention rates. This is a research study that has been approved by the Internal Review Board of West Virginia University. The data will be collected through a Leadership Practices Inventory (LPI), interviews, and document collection from which it may be possible to develop a theory related to the affect that leadership and school culture have on teacher retention. All data collected is a critical component of my doctoral dissertation which will be conducted under the direction of Dr. Paul Chapman, Professor of Educational Leadership Studies at West Virginia University.

By volunteering to have me come visit your school for a period of not more than fifteen days, you will provide valuable data for the research study. The fifteen day visit will occur at a time you and your staff so indicate. During the visit, I will be interviewing teachers and principals who wish to volunteer. In addition, I will be seeking information through the study of documents such as memoranda, e-mails, press releases, faculty meeting agendas, and any financial records that you choose to share.

The following assurances, as required by West Virginia University, will be respected: participation in the study is voluntary; information will be kept as confidential as legally possible; and the participant may refuse to participate, quit at any time, or skip any questions with no negative effect in employment status. Further, West Virginia University's Institutional Review Board acknowledgement for this research is on file.

Thank you for considering my presence at your school for approximately three to five days.

Sincerely,

Paul Chapman, Principal Investigator Educational Leadership Associate Professor
Ronald A. Branch II, Primary Contact Doctoral Student 


\section{APPENDIX B \\ Principal Interview Protocol}

\section{Script:}

Hello, my name is Ron Branch. I am a doctoral student in West Virginia University's educational leadership program. I would like to thank you for agreeing to participate in the study on the leadership practices and cultural aspects that lead to high teacher retention. Through the interview process of administrators and teachers, I hope to gather information that will assist in finding the leadership practices and cultural aspects of schools that lead to high teacher retention.

Your participation is entirely voluntary and you will not have to answer each question. You have my assurance that your responses will remain anonymous and that confidentiality will be maintained throughout the data collection and reporting processes.

It is my goal to be able to specifically identify the leadership practices and cultural aspects of schools that retain a high rate of teachers. Over the past three years, this school has shown the highest rate of teacher retention in this programmatic level in Berkeley County, West Virginia. You will complete an LPI concerning your own practices and be asked a series of interview questions that are intended to identify the leadership practices and cultural aspects that are in place at your school. I may also contact you at a later date, if questions arise about this interview. Please feel free to contact me if you have any questions or additional thoughts.

Do I have your permission to record this interview and take notes to ensure the accuracy of your responses? yes no

Do you have any questions before we begin? yes no

School name: 


\section{Principal Interview Questions}

1. In what ways do you set an example of what you expect from others?

2. What is the vision of the school?

3. What leadership practices do you employ that you believe to be essential in creating the shared vision of the school?

4. What methods of communication do you employ?

5. What do you notice about your role in the professional development of the faculty?

6. What innovative instructional strategies do you encourage teachers to use in their classes?

7. In what ways have teachers been able to participate in school-based decisions and activities?

8. What methods do you use to gather input from the faculty?

9. In what ways have you rewarded the staff or recognized their work?

10. What encouraging remarks have you made toward staff members or students?

11. What types of leadership strategies do you employ that make teachers want to stay at this school?

12. What types of activities do teachers participate in that make them feel like an integral part of the school?

13. What types of interactions take place between you and faculty members that you believe are important to making teachers want to stay at this school?

14. What types of relationships do you notice among staff members that make teachers want to stay in this school? 
15. How do you feel about coming to work at this school?

16. Why do you believe that this school is a better place to work than other schools?

17. What cultural aspects of your school make it unique in comparison to other schools?

18. What experiences have helped create your perception of the culture of this school?

19. What beliefs about education are promoted among the faculty and staff of the school?

20. What do you notice about the appearance of the school?

21. How do you believe you create a positive school culture?

22. What are your overall perceptions of the culture of the school?

23. What cultural conditions make teachers want to stay at this school?

24. What is your experience in the field of education?

\section{Closing}

1. We've talked about the leadership practices and cultural aspects relevant to this school. Are there other aspects within the school that you would like to discuss regarding leadership practices or school culture as they relate to teacher retention? 


\author{
APPENDIX C \\ Request for staff member participation
}

\title{
(Date)
}

(School address)

\section{Dear Staff Member:}

My name is Ron Branch and I am writing to request your participation in a case study whose purpose is to gather information that will assist in finding the leadership practices and cultural aspects of schools that lead to high teacher retention. This is a research study that has been approved by the Internal Review Board of West Virginia University. A benefit of your participation in this study is the opportunity for you to provide answers as to the leadership practices and cultural elements that are prevalent within your school. The data will be collected through a Leadership Practices Inventory (LPI) of your principal, interviews, and document collection from which it may be possible to develop a theory related to the affect that leadership and school culture have on teacher retention. All data collected is a critical component of my doctoral dissertation which will be conducted under the direction of Dr. Paul Chapman, Professor of Educational Leadership Studies at West Virginia University.

By volunteering to participate in this study, you agree to complete an LPI of your principal, and you may be randomly selected to participate in an interview, using a set of semi-structured questions. These interviews will be audio-taped. You may inform me if you wish not to be audio-taped during the interview. The data collected through the LPI and interview process is crucial in the development of possible theory regarding the leadership practices and cultural elements of a school that lead to a high rate of teacher retention.

The following assurances, as required by West Virginia University, will be respected: participation in the study is voluntary; information will be kept as confidential as legally possible; and the participant may refuse to participate, quit at any time, or skip any questions with no negative effect in employment status. Further, West Virginia University's Institutional Review Board acknowledgement for this research is on file.

Thank you for your consideration in this request.

Sincerely,

Paul Chapman, Principal Investigator Educational Leadership Associate Professor
Ronald A. Branch II, Primary Contact Doctoral Student 


\section{APPENDIX D}

\section{Script:}

\section{Staff Member Interview Protocol}

Hello, my name is Ron Branch. I am a doctoral student in West Virginia University's educational leadership program. I would like to thank you for agreeing to participate in the study on the leadership practices and cultural aspects that lead to high teacher retention. Through the interview process of administrators and teachers, I hope to gather information that will assist in finding the leadership practices and cultural aspects of schools that lead to high teacher retention.

Your participation is entirely voluntary and you will not have to answer each question. You have my assurance that your responses will remain anonymous and that confidentiality will be maintained throughout the data collection and reporting processes.

It is my goal to be able to specifically identify the leadership practices and cultural aspects of schools that retain a high rate of teachers. Over the past three years, this school has shown the highest rate of teacher retention in this programmatic level in Berkeley County, West Virginia. You will complete an LPI concerning your principal's practices and will be asked a series of interview questions that are intended to identify the leadership practices and cultural aspects that are in place at your school. I may also contact you at a later date, if questions arise about this interview. Please feel free to contact me if you have any questions or additional thoughts.

Do I have your permission to record this interview and take notes to ensure the accuracy of your responses? yes no

Do you have any questions before we begin? yes no

School name: 


\section{Staff Member Interview Questions}

1. In what ways does the principal set an example of what he expects from others?

2. What is the vision of the school?

3. What leadership practices are employed by the principal that you believe to be essential in creating the shared vision of the school?

4. What methods of communication does the principal employ?

5. What do you notice about the principal's role in the professional development of the faculty?

6. What innovative instructional strategies does the principal encourage teachers to use in their classes?

7. In what ways have you been able to participate in school-based decisions and activities?

8. What are the methods used by the principal to gather input from the faculty?

9. In what ways has the principal rewarded you or recognized your work?

10. What encouraging remarks have you heard the principal make toward other staff members or students?

11. What types of leadership strategies are employed by the principal that make you want to stay at this school?

12. What types of activities do you participate in that make you feel like an integral part of the school? 
13. What types of interactions take place between the principal and faculty members that you believe are important to making teachers want to stay at this school?

14. What types of relationships do you notice among staff members that make teachers want to stay in this school?

15. How do you feel about coming to work at this school?

16. Why do you believe that this school is a better place to work than other schools?

17. What cultural aspects of your school make it unique in comparison to other schools?

18. What experiences have helped create your perception of the culture of this school?

19. What beliefs about education are promoted among the faculty and staff of the school?

20. What do you notice about the appearance of the school?

21. How do you believe the principal creates a positive school culture?

22. What are your overall perceptions of the culture of the school?

23. What cultural conditions make you want to stay at this school?

24. What is your experience in the field of education? 


\section{Closing}

1. We've talked about the leadership practices and cultural aspects relevant to this school. Are there other aspects within the school that you would like to discuss regarding leadership practices or school culture as they relate to teacher retention? 


\author{
APPENDIX E \\ Request for county administrator participation
}

(Date)

(County board office address)

Dear Administrator:

My name is Ron Branch and I am writing to request your participation in a case study whose purpose is to gather information that will assist in finding the leadership practices and cultural aspects of schools that lead to high teacher retention. This is a research study that has been approved by the Internal Review Board of West Virginia University. A benefit of your participation in this study is the opportunity for you to provide answers as to the leadership practices and cultural elements that are prevalent within schools in Berkeley County. The data will be collected through a Leadership Practices Inventory (LPI) of the school principal, interviews, and document collection from which it may be possible to develop a theory related to the affect that leadership and school culture have on teacher retention. All data collected is a critical component of my doctoral dissertation which will be conducted under the direction of Dr. Paul Chapman, Professor of Educational Leadership Studies at West Virginia University.

By volunteering to participate in this study, you agree to complete an LPI of the school principal, and you will be interviewed using a set of semi-structured questions. The interview will be audio-taped. If you wish not to be audio-taped during the interview, you may let me know. This data is crucial in the development of possible theory regarding the leadership practices and cultural elements of a school that lead to a high rate of teacher retention.

The following assurances, as required by West Virginia University, will be respected: participation in the study is voluntary; information will be kept as confidential as legally possible; and the participant may refuse to participate, quit at any time, or skip any questions with no negative effect in employment status. Further, West Virginia University's Institutional Review Board acknowledgement for this research is on file.

Thank you for your consideration in this request.

Sincerely,

Paul Chapman, Principal Investigator

Educational Leadership Associate Professor
Ronald A. Branch II, Primary Contact Doctoral Student 


\section{APPENDIX F}

\section{Seript:}

\section{County Administrator Interview Protocol}

Hello, my name is Ron Branch. I am a doctoral student in West Virginia University's educational leadership program. I would like to thank you for agreeing to participate in the study on the leadership practices and cultural aspects that lead to high teacher retention. Through the interview process of administrators and teachers, I hope to gather information that will assist in finding the leadership practices and cultural aspects of schools that lead to high teacher retention.

Your participation is entirely voluntary and you will not have to answer each question. You have my assurance that your responses will remain anonymous and that confidentiality will be maintained throughout the data collection and reporting processes.

It is my goal to be able to specifically identify the leadership practices and cultural aspects of schools that retain a high rate of teachers. Over the past three years, this school has shown the highest rate of teacher retention in this programmatic level in Berkeley County, West Virginia. You will complete an LPI concerning the principal's practices and be asked a series of interview questions that are intended to identify the leadership practices and cultural aspects that are in place at this school. I may also contact you at a later date, if questions arise about this interview. Please feel free to contact me if you have any questions or additional thoughts.

Do I have your permission to record this interview and take notes to ensure the accuracy of your responses? yes no

Do you have any questions before we begin? yes no

School name: 


\section{County Administrator Interview Questions}

1. What is your association with this school?

2. In what ways does the principal set an example of what he expects from others?

3. What is the vision of the school?

4. What leadership practices are employed by the principal that you believe to be essential in creating the shared vision of the school?

5. What methods of communication does the principal employ?

6. What do you notice about the principal's role in the professional development of the faculty?

7. What innovative instructional strategies does the principal encourage teachers to use in their classes?

8. In what ways have teachers been able to participate in school-based decisions and activities?

9. What are the methods used by the principal to gather input from the faculty?

10. In what ways has the principal rewarded the staff or recognized their work?

11. What encouraging remarks have you heard the principal make toward staff members or students?

12. What types of leadership strategies are employed by the principal that make teachers want to stay at this school?

13. What types of activities do teachers participate in that make them feel like an integral part of the school? 
14. What types of interactions take place between the principal and faculty members that you believe are important to making teachers want to stay at this school?

15. What types of relationships do you notice among staff members that make teachers want to stay in this school?

16. How do you feel about working with this school?

17. Why do you believe that this school is a better place to work than other schools?

18. What cultural aspects of this school make it unique in comparison to other schools?

19. What experiences have helped create your perception of the culture of this school?

20. What beliefs about education are promoted among the faculty and staff of the school?

21. What do you notice about the appearance of the school?

22. How do you believe the principal creates a positive school culture?

23. What are your overall perceptions of the culture of the school?

24. What cultural conditions make teachers want to stay at this school?

25. What is your experience in the field of education? 


\section{Closing}

1. We've talked about the leadership practices and cultural aspects relevant to this school. Are there other aspects within the school that you would like to discuss regarding leadership practices or school culture as they relate to teacher retention? 